\title{
LOS CATÁLOGOS DE MATERIAL ESCOLAR COMO FUENTE DE LA HISTORIA DE LA EDUCACIÓN MATEMÁTICA: EL CASO DE LOS ÁBACOS ${ }^{1 \&}$
}

\author{
The catalogues of school supplies as a source for the History of \\ Mathematics Education: the case of the abacus
}

\section{Dolores Carrillo Gallego*}

Fecha de recepción: 13/03/2017 • Fecha de aceptación: 30/08/2017

Resumen. En este trabajo se pretende estudiar el potencial que tienen los catálogos de material escolar como fuente para el estudio de la Historia de la Educación Matemática (HEM). En primer lugar, se describen algunas características de los catálogos de material escolar a tener en cuenta cuando se utilizan como fuente histórica. A continuación, se analiza cómo aparece en un conjunto de catálogos un material muy característico de la enseñanza de la aritmética: los ábacos. Para poder realizar ese análisis se dedica un apartado a caracterizar los ábacos escolares y su uso. Los aparatos ofertados en los catálogos se han caracterizado a partir de la descripción y las imágenes de los mismos. La existencia de series temporales en los documentos utilizados ha permitido valorar la estabilidad y el cambio en la oferta que se realizaba. Este análisis de los ábacos que aparecen en los catálogos nos permitirá valorar los catálogos como fuente para la HEM.

Palabras clave: Catálogos; Material escolar; Ábaco; Tablero contador.

Abstract. In this work we study school supply catalogues as a source for the study of History of Mathematics Education (HME). First, we describe some relevant characteristics of school supply catalogues when used as historical sources. Then, we analyse how abacuses appear in some sets of catalogues as a typical tool for teaching arithmetic. For this purpose, we devote a section to describing school abacuses and their uses. We describe the devices offered in catalogues

\footnotetext{
\& El trabajo forma parte de un proyecto de investigación en curso, financiado por el Ministerio de Economía y Competitividad EDU2013-42040-P, titulado «Imagen y educación: marketing, comercialización, didáctica (España, siglo Xx)».

* Departamento de Didáctica de las Ciencias Matemáticas y Sociales, Facultad de Educación, Universidad de Murcia. Facultad de Educación. Campus universitario de Espinardo. 30100 Murcia. España.carrillo@um.es
}

Cómo citar este artículo: Carrillo Gallego, Dolores. «Los catálogos de material escolar como fuente de la historia de la educación matemática: el caso de los ábacos». Historia y Memoria de la Educación 7 (2018): 573-613. 
according to their description and images. The existence of diachronic series of documents allows us to assess the degree to which the offer remained stable or changed as time passed. This analysis of abacuses appearing in catalogues will allow us to appreciate catalogues as a source material for HME.

Keywords: Catalogues; School supplies; Abacus; Counters.

La Historia de la Educación Matemática (HEM) no puede limitarse al conocimiento de los programas de las asignaturas de matemáticas, las leyes a las que responden o los libros de texto utilizados en su enseñanza. También son importantes los estudios sobre las prácticas que se desarrollan efectivamente dentro del aula con la finalidad de que los alumnos adquieran conocimientos matemáticos. Se trata de uno de los últimos niveles de la transposición didáctica del conocimiento, un aspecto relevante de lo que Dominique Julia denomina la cultura escolar: «un conjunto de normas que definen los saberes a enseñar y los comportamientos a inculcar, y un conjunto de prácticas que permiten la transmisión y la asimilación de dichos saberes y la incorporación de estos procedimientos». ${ }^{1}$

Antonio Viñao considera que la cultura material es uno de los componentes fundamentales de esa cultura escolar. Dentro de la cultura material sitúa los materiales de enseñanza ${ }^{2}$ construidos y comercializados por diversas casas comerciales que los publicitaban mediante la edición de catálogos dedicados total o parcialmente a los mismos.

Por tanto, los catálogos de material escolar son una fuente importante para conocer qué materiales podría haber en las aulas en un determinado periodo y la función que tenían en los procesos de enseñanza y aprendizaje. Un catálogo de material escolar provoca sentimientos parecidos a la vista de un aula de clase de otra época. En sus páginas encontramos testimonios que, a priori, podemos considerar valiosos para conocer la historia de la escuela.

El primer estudio que se realiza en España en el que se utilizan los catálogos como fuente de la historia de la educación es el de León Esteban. ${ }^{3}$

\footnotetext{
${ }^{1}$ Dominique Julia, «La culture scolaire comme objet historique», en Colonial experience in Education. Historical Issues and Perspectives (Gante: Paedagogica Historica, Supplementary series (I), 1995), 354.

${ }^{2}$ Antonio Viñao, Sistemas educativos, culturas escolares y reformas (Madrid: Morata, 2002), 75.

${ }^{3}$ León Esteban, «Los catálogos de librería y material de enseñanza como fuente iconográfica y literario escolar», Historia de la Educación, 16 (1997): 17-46.
} 
Posteriormente se han utilizado para estudiar aspectos específicos de la cultura material de los centros educativos en relación con determinados fondos de catálogos, ${ }^{4}$ o con el mobiliario escolar, ${ }^{5}$ el material del método Froebel $^{6}$ o el material científico. ${ }^{7}$

La cuestión germinal de este trabajo es: ¿Qué aportan los catálogos de material escolar al conocimiento de la Historia de la Educación Matemática (HEM)? Para dar una respuesta hay que indagar en varias direcciones y aparecen nuevas cuestiones como:

A) Conocer qué son los catálogos, sus características, su función para las casas comerciales y sus clientes.

B) Estabilidad y cambio en las propuestas de los catálogos.

C) ¿Qué relación existe entre las propuestas de los catálogos y las metodologías que se difunden en libros y artículos?

D) ¿Qué relación existe entre las propuestas de los catálogos y las prácticas efectivas de aula?

Son cuestiones que se refieren a las posibilidades y límites de los catálogos como fuente para la HEM. El análisis de las propuestas de los catálogos en relación con los ábacos puede avanzar respuestas a las mismas. En este trabajo abordaremos aquellas que se podrían denominar intraca-

\footnotetext{
${ }^{4}$ Pedro Luis Moreno, y Ana Sebastián, «Los catálogos de material de enseñanza y la cultura material de la escuela. La colección del Centro de Estudios sobre la memoria Educativa (CEME) de la Universidad de Murcia». En Patrimonio y Etnografía en España y Portugal durante el siglo XX, eds. Pedro L. Moreno Martínez, Ana Sebastián Vicente (Murcia: Sociedad Española para el Estudio del Patrimonio Histórico-Educativo (SEPHE) y Centro de Estudios sobre la Memoria Educativa (CEME) de la Universidad de Murcia, 2012), 293-309.

${ }^{5}$ Pedro Luis Moreno, «History of School Desk Development in Terms of Hygiene and Pedagogy in Spain (1838-1936)», en Materialities of Schooling: Design - Tecnology - Objects - Routines, eds. M. Lawn, y I. Grosvenor (Oxford: Symposium books, 2005), 71-95, y «El mobiliario escolar en los catálogos de material de enseñanza: consideraciones metodológicas», en La infancia en la historia: espacios y representaciones, eds. P. Dávila y L.M. Naya, (San Sebastián: Erein, 2005) Vol. 1, 342-355.

${ }^{6}$ María José Martínez Ruiz-Funes, «Los catálogos de material de enseñanza como fuente para el estudio de la cultura material: la recepción y difusión del Método Froebel en España», en Patrimonio y Etnografía en España y Portugal durante el siglo XX, 265-277.

${ }^{7}$ José Mariano Bernal, José Damián López y Pedro Luis Moreno, «Museos pedagógicos y enseñanza de las ciencias: de las láminas y colecciones a los recursos didácticos virtuales», en I Encontro Iberoamericano de Museos Pedagóxicos y museólogos de la educación (Santiago de Compostela: Xunta de Galicia, 2008), 413-426.
} 
tálogos, pero nuestro estudio se completa con el análisis de las cuestiones C y D más relacionados con la HEM.

¿Por qué utilizar los ábacos para este estudio?

La primera razón es que los ábacos se perciben como una imagen prototípica de la escuela y de la aritmética escolar; y eso es así incluso aunque no se recuerde o se conozca su uso. En demasiadas ocasiones la imagen que se presenta del ábaco es errónea, y los errores nos sugieren que quienes han seleccionado la imagen desconocen cómo son los ábacos y su utilización. Veamos dos ejemplos.

Se encuentran en espacios museísticos sobre la escuela ábacos que no tienen las diez bolas por alambre, por lo que no pueden ser utilizados como tales; seguramente eran aparatos rotos que no se han reconstruido bien.

Otro ejemplo es la portada de un libro de texto de hace pocos años (figura 1). ${ }^{8}$ En ella aparece un ábaco imposible, con una cantidad aleatoria de bolas en cada alambre. No es un caso aislado.
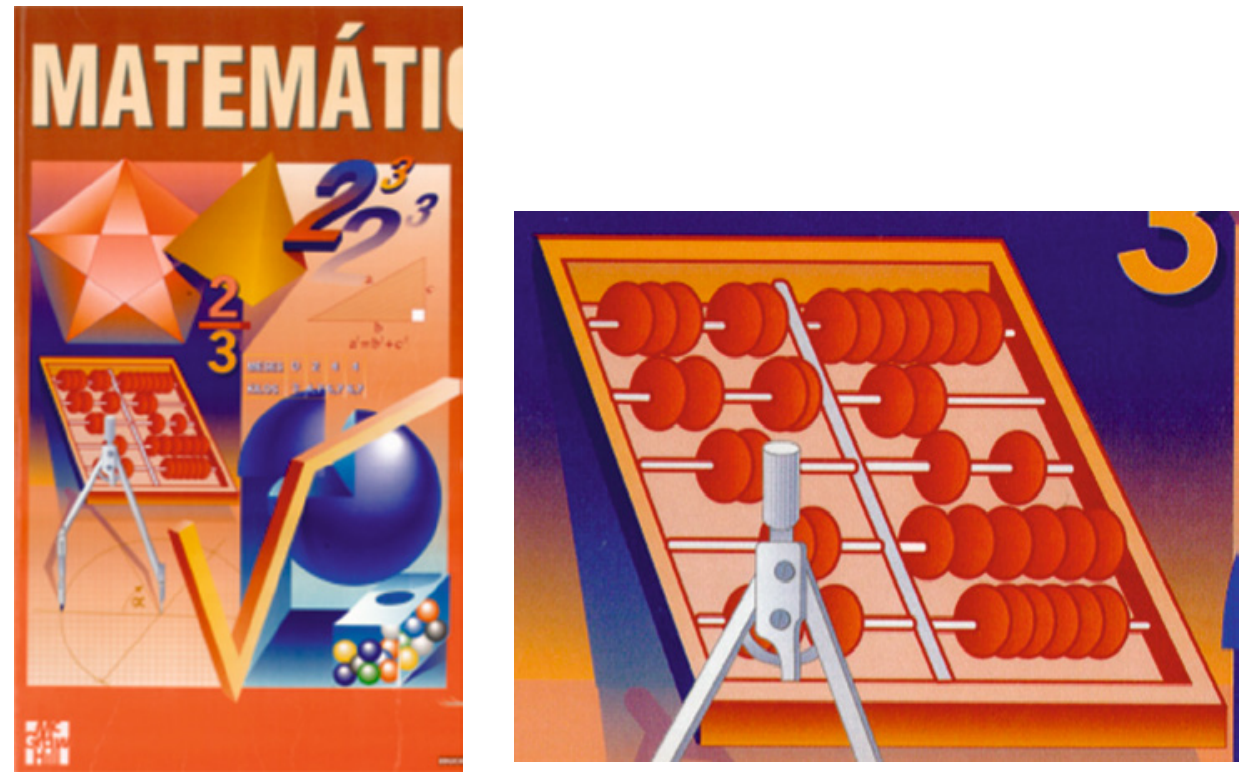

Figura 1. Ábaco en la portada de un libro de ESO.

\footnotetext{
${ }^{8}$ Luis Pancorbo et al., Matemáticas 1 (Madrid: Mc Graw Hill, 1995).
} 
Otra razón para utilizarlos en este estudio es que los ábacos son un material que suele aparecer en los catálogos, y cuyo uso escolar experimentó una evolución a lo largo del periodo que puede o no ser recogida en los mismos.

El estudio de la pertinencia de los ábacos para el análisis de los catálogos como fuente para la historia de la educación matemática plantea, cómo cuestión previa, la caracterización de los ábacos y sus usos.

\section{LOS CATÁLOGOS DE MATERIAL ESCOLAR}

Los catálogos de material escolar ${ }^{9}$ son un producto eminentemente comercial, editado por fabricantes, distribuidores o, en general, casas comerciales, para dar publicidad a objetos que pueden ser adquiridos por centros de enseñanza.

Las casas comerciales podían editar diferentes tipos de catálogos. En la colección que posee el Centro de Estudios sobre la Memoria Educativa (CEME) de la Universidad de Murcia hay catálogos generales, que recogen tanto libros como otros tipos de material de enseñanza; otros son exclusivamente bibliográficos, y otros recogen material escolar no bibliográfico; entre estos últimos los hay específicos, como los dedicados al mobiliario escolar, a aparatos de proyección, a material de física y química, etc. ${ }^{10}$

La procedencia de los objetos ofertados por los catálogos es diversa y depende de las características de la casa comercial. A veces son objetos fabricados por los editores del catálogo; en otras ocasiones la casa comercializa productos de otras empresas nacionales o extranjeras, productos que pueden tener almacenados o que, simplemente, son capaces de adquirir.

Los catálogos de material escolar permiten la difusión de medios para la enseñanza más o menos novedosos y posibilitan el acceso a los mismos por parte de centros escolares, profesores y alumnos.

\footnotetext{
${ }^{9}$ Sobre la caracterización de los catálogos de material escolar puede consultarse Esteban, «Los catálogos de librería y material de enseñanza», 18, Moreno y Sebastián, «Los catálogos de material de enseñanza», 295, y Martínez Ruiz-Funes, «Los catálogos de material de enseñanza», 266.

${ }^{10}$ Moreno y Sebastián, «Los catálogos de material de enseñanza», 302-304.
} 


\section{Los catálogos como fuente de la Historia de la Educación}

Como afirma Pedro Luis Moreno, los catálogos comerciales «constituyen una fuente novedosa fundamental para profundizar en el conocimiento, entre otros sectores de la historia de la educación, en los de la historia material de la escuela, la historia del currículum o la historia de la escuela». ${ }^{11}$ Las potencialidades de esta fuente son estudiadas por Moreno en dicho trabajo, aplicándolas al estudio del mobiliario escolar.

Los catálogos informan sobre qué materiales se comercializan y, por tanto, pueden estar disponibles en las aulas. Aunque esos datos tienen que ser contrastados con fuentes de otro tipo como los documentos legales, en particular los que se refieren al material didáctico, los indicadores de su adquisición efectiva por los centros educativos, y la descripción de su uso contenida en obras especializadas y en artículos sobre prácticas escolares en el aula. También se pueden considerar los anuncios en revistas profesionales. Este tipo de fuente está muy relacionada con los propios catálogos, pues son anuncios de las casas comerciales que publicitan alguno de sus productos, bien los de mayor utilización, bien los de mayor interés o novedad.

Pero hay que tener en cuenta la caducidad de los catálogos, que quedan obsoletos al poco tiempo. Al modificarse el precio o las condiciones de comercialización, las casas editan nuevos catálogos que anulan los anteriores, que suelen destruirse. Generalmente los catálogos se regalan o tienen un precio simbólico. Por eso suelen presentar en ocasiones encuadernaciones muy sencillas, fácilmente deteriorables; además, como señala Moreno, ${ }^{12}$ "estas fuentes no se han conservado con la profusión que hubiera sido deseable». Es difícil conseguir series completas de una casa editorial para realizar comparaciones. Incluso la numeración cambiante de algunas casas comerciales dificulta la identificación de la serie completa de catálogos de dicha casa. ${ }^{13}$

\footnotetext{
${ }^{11}$ Moreno, «El mobiliario escolar en los catálogos de material de enseñanza», 343.

12 Moreno, «El mobiliario escolar en los catálogos de material de enseñanza», 345.

${ }^{13}$ Un ejemplo son los catálogos de la casa Cultura utilizados en este trabajo. Además, en 1962 publicaron el catálogo número 100, en 1964 el número 200 y en 1967 el número 300.
} 
Los estudios históricos son muy dependientes de las fuentes disponibles y la aparición de nuevos datos puede suponer la revisión de los mismos. Y eso ocurre cuando se utilizan los catálogos de material escolar.

Las posibilidades y límites de los catálogos como fuente para el estudio de la Historia de la Educación Matemática pueden verse al estudiar cómo aparecen los ábacos en los mismos.

\section{Los catálogos utilizados en este estudio}

Los catálogos seleccionados para este estudio forman parte del fondo del Centro de Estudios sobre la Memoria Educativa de la Universidad de Murcia y pertenecen periodo 1881-1936. En este periodo la industria editorial en España tuvo bastante estabilidad. El límite inferior lo marca el catálogo de material escolar más antiguo de que disponemos; el límite superior es la fecha del comienzo de la guerra civil española. No se han utilizado catálogos posteriores porque la situación de la industria española, la posibilidad de importar material y la propia orientación de las enseñanzas fue muy diferente.

En la siguiente relación figuran los catálogos utilizados.

Librería Juan y Antonio Bastinos, Catálogo de los efectos y libros propios de la casa (Barcelona: Juan y Antonio Bastinos, 1881).

Antonio J. Bastinos, Catálogo Ilustrado de los Productos de esta Casa. Libros y Material Escolar (Barcelona: Antonio J. Bastinos Editor, 1897).

Librería Hispano-Americana Sucesores de Julián Bastinos, Catálogo General de las Obras de Primera Enseñanza de texto y consulta y material para escuelas (Barcelona: Imprenta de Francisco Badía, 1905).

Bazar Ibérico, Catálogo general ilustrado de material instructivo moderno para escuelas Elementales, Superiores, Normales y de Comercio, Institutos, Universidades y enseñanzas especiales (Barcelona: Bazar Ibérico, 1914).

Cultura. Juan Eimler, Catálogo de Material Pedagógico Moderno (Madrid: Cultura. Eimler-Basanta-Haase S.L., 1925).

Cultura. Eimler-Basanta-Haase S.L., Catálogo de Material de Enseñanza. Resumen general. Catálogo VI (Madrid: Cultura. Eimler-Basanta-Haase S.L., 1927).

Cultura. Eimler-Basanta-Haase S.L., Catálogo XX para institutos, escuelas normales y demás centros docentes (Madrid: Cultura. Eimler-Basanta-Haase S.L., 1932). 
Cultura. Eimler-Basanta-Haase S.L., Material Pedagógico Moderno para Universidades, Institutos, Escuelas Normales, Escuelas Nacionales y demás centros docentes (Catálogo 30) (Madrid: Cultura. Eimler-Basanta-Haase S.L., 1934).

Dalmau Carles, Pla, Catálogo de Material Escolar de la editorial Dalmau Carles, Pla. Curso 1935-1936 (Gerona- Madrid: Dalmau Carles. 1935).

Espasa-Calpe, Material de Enseñanza. Catálogo General (Madrid: Espasa-Calpe, 1934).

Librería de la Viuda de Hernando y Cia., Catálogo del Material y efectos para las clases, libros de primera enseñanza y obras de consulta y de utilidad para los maestros (Madrid: Librería de la Viuda de Hernando, 1892).

Librería de la Viuda de Hernando y Cia., Catálogo de Material, libros de texto para institutos, escuelas normales y seminarios de carreras especiales (Madrid: Viuda de Hernando y Cia., 1894).

Librería y Casa Editorial Hernando S.A., Catálogo de Material de Enseñanza y Mobiliario Escolar para toda clase de establecimientos docentes (Madrid: Imprenta de la Librería y Casa Editorial Hernando S.A., 1933).

K.F. Koehler, Catálogo ilustrado de material de enseñanza. Lista de los aparatos y útiles más modernos y adecuados para la enseñanza objetiva, aprobados y en uso en las escuelas de Alemania. Segunda edición (Leipzig: Koehler, s.f.).

Koeler \& Volckmar A.-G. \& Co., Catálogo General Ilustrado de Material Pedagógico Moderno. Material y utensilios seleccionados cuidadosamente para escuelas, Institutos y Universidades de España y de América central y Meridional (Leipzig (Alemania): Koeler \& Volckmar A.-G. \& Co., 1928).

El Magisterio Español, Catálogo General de Obras de Pedagogía (Madrid: Editorial Magisterio Español, s.f.).

Perelló y Vergés, Catálogo General Ilustrado de material de enseñanza y librería (Barcelona: Perelló y Vergés, 1915).

Librería escolar de Antonio Pérez, Catálogo Ilustrado de Material de Enseñaza, objetos de escritorio y dibujo; libros, premios, obras religiosas etc... (Madrid: Antonio Pérez, 1911).

Hijos de Antonio Pérez, Catálogo Ilustrado de la Librería Escolar (Madrid: Hijos de Antonio Pérez, 1930).

Librería Matías Real, Catálogo de obras de Primera Enseñanza y Libros de Consulta y de Utilidad para los Maestros. Material y Efectos para toda clase de Establecimientos Docentes. Obras Religiosas de Devoción. Libros y Objetos para Premios (Valencia: Librería de Matías Real, 1907).

Fernando Santarén Madrazo, Catálogo General (Valladolid: Fernando Santarén Madrazo, s.f.). 
F. Volckmar, Catálogo general con un sinnúmero de grabados é ilustraciones en colores de material de enseñanza y útiles para escuelas (Leipzig: Volckmar, 1910).

Las casas comerciales que editan estos catálogos son de distinto tipo. Algunas tienen su origen en librerías e imprentas. Suelen ofrecer, como en el caso de Pérez (1911), «material de enseñanza, objetos de escritorio y dibujo; libros, premios, obras religiosas, etc.», y están en relación con «Autores, Editores y Casas extranjeras». En este grupo se sitúan Pérez (1930), Santarem, Real (1907) y Perelló y Vergés (1915).

Otro grupo son casas editoriales, sobre todo de libros dedicados a la enseñanza, que ofrecen también materiales escolares, como son los casos de la casa Hernando $(1892,1894,1933)$ y Magisterio Español.

Hay casas editoriales que fabrican, en parte, los materiales que ofrecen, aunque también incluyan en sus catálogos otros objetos, en particular, importados. Así ocurre con la casa Bastinos (1881, 1897 y 1905), que ofrece «libros y material de enseñanza propios de esta casa, y á nuestra iniciativa debidos en su mayor parte, editados ó fabricados bajo nuestra dirección», ${ }^{14}$ y Dalmau Carles, Pla y Espasa Calpe que importan objetos, pero también construyen material científico destinado fundamentalmente a la segunda enseñanza.

Hay casas comerciales que se dedican primordialmente al material de enseñanza. Por ejemplo, la casa Cultura (1925, 1927, 1932 y 1935) que afirma que «merced a nuestras excelentes relaciones [...] hemos podido hacer una elección y clasificación del material pedagógico más conveniente para la enseñanza en España»; ${ }^{15}$ esta casa elaboró un gran número de catálogos especializados en diversos materiales. La casa Bazar Ibérico también se dedica fundamentalmente a la distribución de material para la enseñanza, especialmente extranjero, y es la representante para el centro y sur de España de la casa American Seating Company, Nueva York-Boston-Filadelfia. Por último, la casa Koehler-Volckmar es una gran empresa alemana, de Leipzig, dedicada a la fabricación de material de enseñanza, que edita catálogos en castellano dedicados el público español e iberoamericano.

${ }^{14}$ Bastinos, Catálogo, 1881, s.p. En las citas textuales se ha respetado la ortografía original.

${ }^{15}$ Cultura, Catálogo, 1925, s.p. 


\section{¿QUÉ ES UN ÁBACO ESCOLAR?}

Los ábacos han sido instrumentos de cálculo en muchas culturas humanas.

Nuestro sistema de numeración posicional ha permitido definir algoritmos, que se realizan «con lápiz y papel», que permiten realizar cálculos numéricos con facilidad. Pero la generalidad de los sistemas de numeración que han empleado las distintas sociedades humanas no han sido de tipo posicional y la realización de operaciones aritméticas con ellos era compleja (pensemos, por ejemplo, en realizar una división con números romanos). Por ello, en cada cultura había modelos de instrumentos de cálculo (ábacos) que, en muchas ocasiones, solo un determinado grupo de personas («calculistas») sabía utilizar. En la figura 2(a) se muestra un ábaco romano y en la parte inferior izquierda de la figura 2(b) aparece el tipo de ábaco que empleaban los quipucamayoc, que eran los calculadores incas. ${ }^{16}$

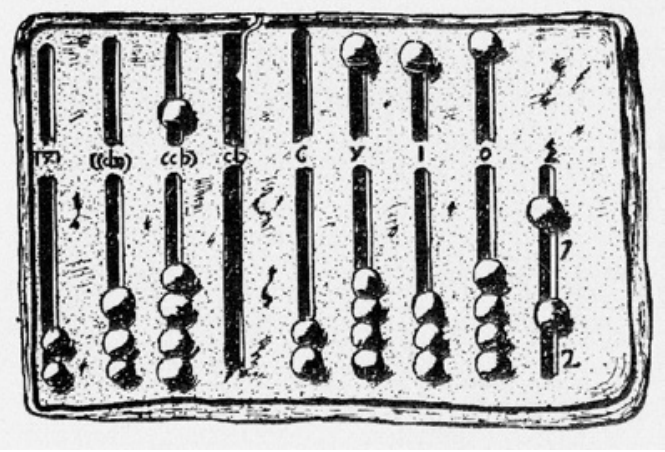

(a)

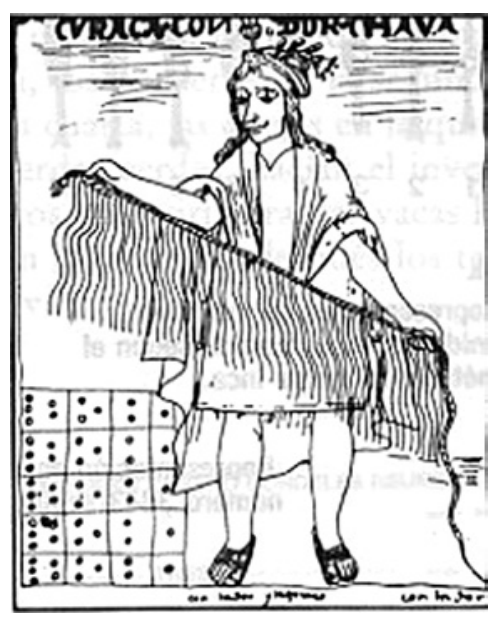

(b)

Figura 2. (a): Ábaco romano. (b): Quipucamayoc, calculista inca con un quipu.

La apariencia de los ábacos es variada, pero en todos ellos hay unos objetos (piedras, bolas, fichas con cifras...) cuyo valor depende de la po${ }^{16}$ G. Ifrah, Las cifras. Historia de una gran invención (Madrid: Alianza Editorial, 1987), 116 y 97,
respectivamente. 
sición que ocupen (ya sea en un alambre, en una cuadrícula, etc.). Es, pues, un material posicional.

En Europa, durante la Edad Media, se utilizaron ábacos para el cálculo. Conforme se fue generalizando el uso del sistema de numeración posicional (de origen hindú y transmitido por los árabes), los cálculos pasaron a hacerse «a pluma», usando algoritmos escritos. En la España del siglo XVI ya no se operaba con ábacos, pero en Francia se utilizaron hasta su prohibición por la Revolución Francesa: «así como un peatón liberado de cualquier peso tiene ventaja sobre el que lleva una carga pesada, así el cálculo con cifras aventaja a los cálculos con las fichas de la tabla de contar». ${ }^{17}$

Sin embargo, pocas décadas después, comenzaron a utilizarse en las escuelas, para el aprendizaje de los números, unos aparatos denominados de diferentes formas tales como tablero contador, ábaco, aritmeticón... ${ }^{18}$

La utilización de estos aparatos se relaciona con la aplicación al aprendizaje de la numeración del principio de intuición formulado por Pestalozzi. Hasta ese momento, el aprendizaje de la numeración en las escuelas se realizaba recitando la sucesión de los nombres de los números y copiando las cifras, pero no se hacía referencia a su uso como cardinal de una colección ni como ordinal de un elemento. Pestalozzi, aplicando su principio de intuición, propuso que el aprendizaje de los primeros números se realizase a partir de colecciones de las que eran cardinal; ${ }^{19}$ estos aprendizajes los encomendaba a las madres y los describió en Cómo Gertrudis educa a sus hijos y en Cartas sobre la educación de los niños. Una vez en la escuela, para el aprendizaje intuitivo de los números (hasta 100) y de las fracciones, ideó unas tablas (figura 3) y ejercicios a realizar sobre ellas. ${ }^{20}$

\footnotetext{
${ }^{17}$ Citado en Ifrah, Las cifras, 301.

${ }^{18}$ Dolores Carrillo Gallego, «Los inicios del ábaco escolar», en Etnohistoria de la escuela. XII Coloquio Nacional de Historia de la Educación, (Burgos, Universidad de Burgos, 2003), 95-106.

19 J.E. Pestalozzi, Cómo Gertrudis enseña a sus hijos. Cartas sobre la educación de los niños. Libros de educación elemental (prólogos) (México: Porrúa, 1980), 88-89.

${ }^{20}$ D.A. Chavannes, Exposicion del método elemental de Henrique Pestalozzi (Madrid: Imprenta de Gomez Fuentenebro, 1807).
} 

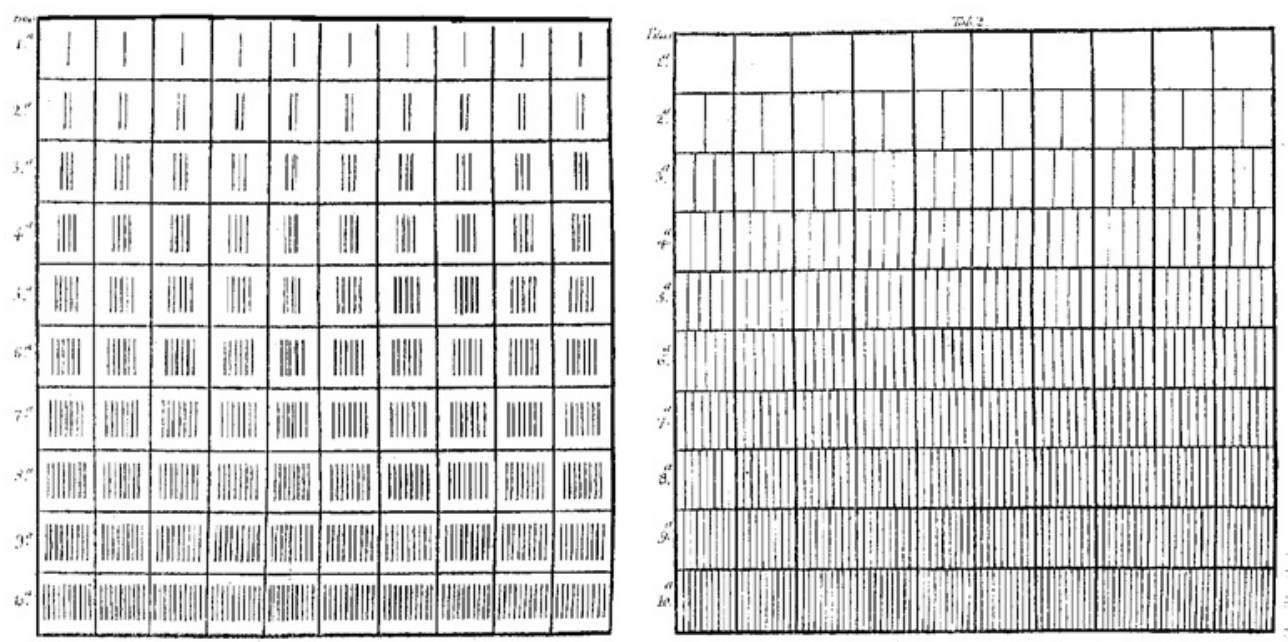

Figura 3. Tablas numéricas de Pestalozzi. Tabla n. ${ }^{\circ} 1$ de enteros y tabla $\mathrm{n} .{ }^{\circ} 2$ de quebrados. ${ }^{21}$

El profesor de Matemáticas del Real Seminario de Nobles de Madrid, José Mariano Vallejo, asistió como observador, en 1807, al Real Instituto Pestalozziano de Madrid y, años después, al realizar un informe a las Cortes como miembro de la Dirección General de Estudios, ${ }^{22}$ criticó la enseñanza aritmética que proponía Pestalozzi.

Con motivo de haber sido nombrado en virtud de Real órden para observar el método de Pestalozzi, en el Instituto que se estableció en Madrid en el año de 1807, dije hace muchos años, que el principio sobre el que se decía estar fundado dicho método, de que todas las ideas primarias se debían adquirir intuitivamente, era el mas exacto que se podía concebir; pero que no era intuitivo todo lo que se enseñaba en el establecimiento que se formó en Madrid para su ensayo. ${ }^{23}$

La Esposición sobre el estado de la enseñanza pública se completaba con un Proyecto de un plan metódico de primera enseñanza presentado á la direc-

\footnotetext{
${ }^{21}$ Chavannes, Exposicion del método elemental de Henrique Pestalozzi, s.p.

${ }^{22}$ Dirección General de Estudios, Esposición sobre el estado de la enseñanza pública, hecha á las Cortes por la Dirección General de Estudios (Madrid: Imprenta de Alban y Cia., 1822).

${ }^{23}$ José Mariano Vallejo, Ideas primarias que deben darse a los niños en las escuelas acerca de los números al tiempo que se están ejercitando en la clave analítica de la lectura (Madrid: Imprenta de D. Miguel de Burgos, 1833), VIII-IX.
} 
cion general de estudios por la comision formada con este objeto elaborado, fundamentalmente, por Vallejo. En lo que se refiere a la enseñanza de la aritmética, ${ }^{24}$ proponía cambiar la tabla $n .{ }^{\circ} 1$ de Pestalozzi por un tablero contador de enteros que describía (figura 4). así como los ejercicios a realizar con él. Esta descripción de un tablero contador es la más antigua que conocemos.

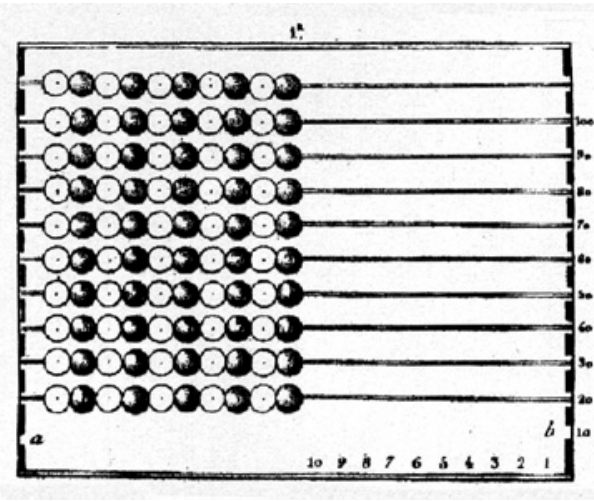

(a)

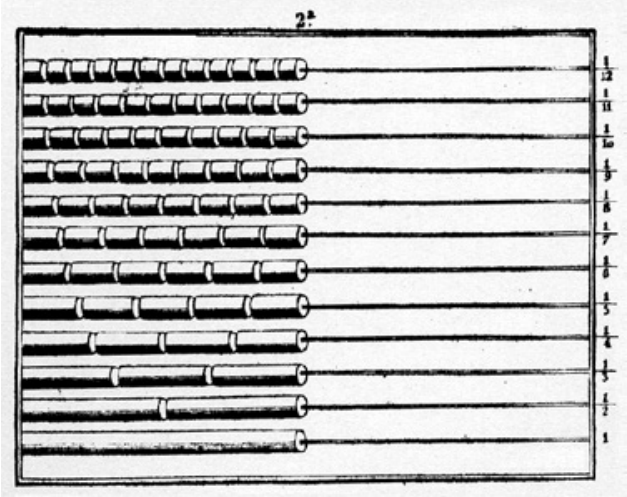

(b)

Figura 4. Bastidores de Vallejo: n. ${ }^{\circ} 1$ de enteros (a) y n. ${ }^{\circ} 2$ de quebrados (b). ${ }^{25}$

Por su implicación política durante el trienio liberal, Vallejo estuvo exiliado hasta 1829. En 1833 publicó una obra ${ }^{26}$ en la que recogía y ampliaba la propuesta que había realizado en 1822 a las Cortes; en esta propuesta se describe el tablero de enteros y uno para el aprendizaje de los quebrados (figura 4). Estos «aparatos» se estuvieron adquiriendo en las escuelas primarias al menos hasta $1870 .{ }^{27}$

Otra persona que propugnó en España el uso de tableros contadores en la escuela fue Pablo Montesino, que los describe en su obra, publicada en 1840, Manual para los maestros de las escuelas de párvulos. Montesino destacaba la importancia del principio de intuición de Pestalozzi para la enseñanza de la aritmética: «en ninguna materia está tan generalmente admitido y tan acreditado como en el primer estudio de los números, des-

\footnotetext{
${ }^{24}$ Dolores Carrillo Gallego, La Metodología de la aritmética en los comienzos de las Escuelas Normales (1838-1868) y sus antecedentes (Murcia: Universidad de Murcia, 2005), 96-100.

${ }^{25}$ Vallejo, Ideas primarias, s.p.

${ }^{26}$ Vallejo, Ideas primarias.

${ }^{27}$ Carrillo Gallego, La Metodología de la aritmética, 110-112.
} 
de que Pestalozzi lo estableció en su escuela y lo dió á conocer», ${ }^{28}$ y afirma que el aprendizaje de los números ha de realizarse a partir de colecciones. Pero no cita las tablas de Pestalozzi y sí un tablero contador como el de Vallejo (figura 5). En el Manual pone como ejemplos de colecciones los dedos de las manos y las bolas del tablero contador. En unos artículos que publicó en $1843,{ }^{29}$ vuelve a recomendar la utilización del tablero contador y de otro tipo de colecciones: fichas, habas, guisantes, garbanzos.

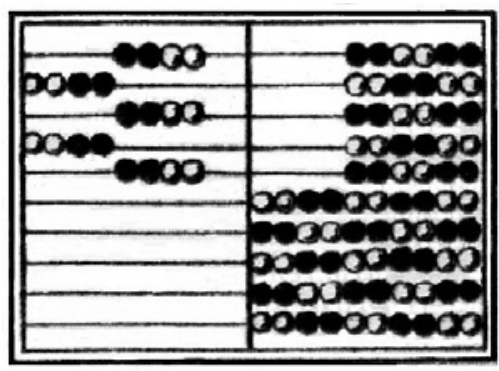

(a)

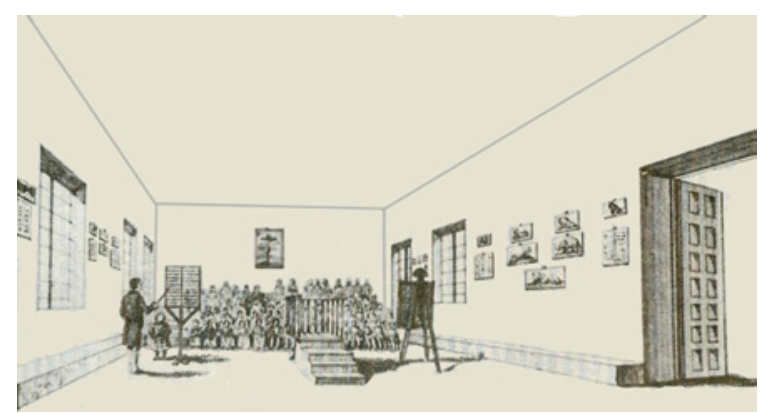

(b)

Figura 5: (a) Tablero contador de Montesino. (b) Aula de párvulos con el maestro usando el tablero contador. ${ }^{30}$

Durante su exilio, Montesino conoció las escuelas inglesas, tanto las de enseñanza mutua como las infant school y en su Manual se advierte la influencia de un maestro de estas escuelas, Samuel Wilderspin. La propuesta que realiza para la enseñanza de la geometría en las escuelas de párvulos es prácticamente idéntica a la de Wilderspin, pero eso no es así en aritmética. Wilderspin también se auxiliaba de tableros de bolas, ${ }^{31}$ pero tanto su estructura como su utilización era diferente. Los tableros que usaba Wilderspin eran uno de 78 bolas, denominado Aritmeticón y otro, similar al tablero contador de Vallejo pero con 12 bolas por fila (figura 6). El tablero contador que propone Montesino, como el de Vallejo, tiene diez bolas por alambre, es decir, una decena, y considera que

\footnotetext{
${ }^{28}$ Pablo Montesino, Manual para los maestros de las escuelas de párvulos (Madrid: Imprenta del colegio de sordo-mudos y ciegos, 1850), 206.

${ }^{29}$ Pablo Montesino (1843): "Métodos especiales de enseñanza. Enseñanza de la aritmética», Boletín Oficial de Instrucción Pública, V (1843): 77-84, 122-128 y 178-190.

${ }^{30}$ Montesino, Manual para los maestros de las escuelas de párvulos. s.p.

${ }^{31}$ Samuel Wilderspin, The infant system for Developing the Intellectual and Moral Powers of all Children, from One to Seven Years of Age (London: James S. Hodson, 1840).
} 
así se le da al niño «una idea exacta de la decena o decenas que está manejando", ${ }^{32}$ lo que no ocurre con los aparatos descritos por Wilderspin.

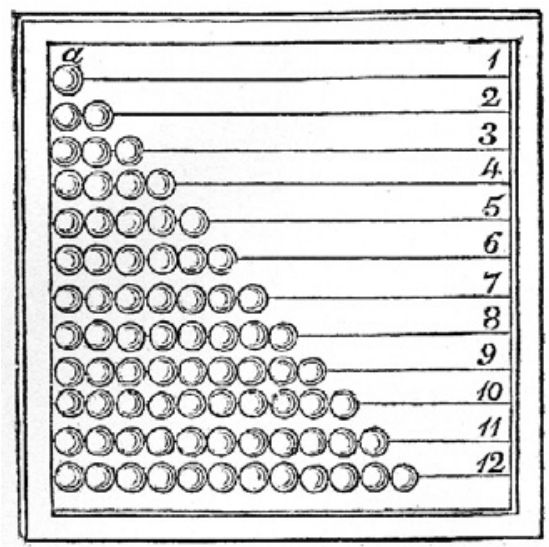

(a)

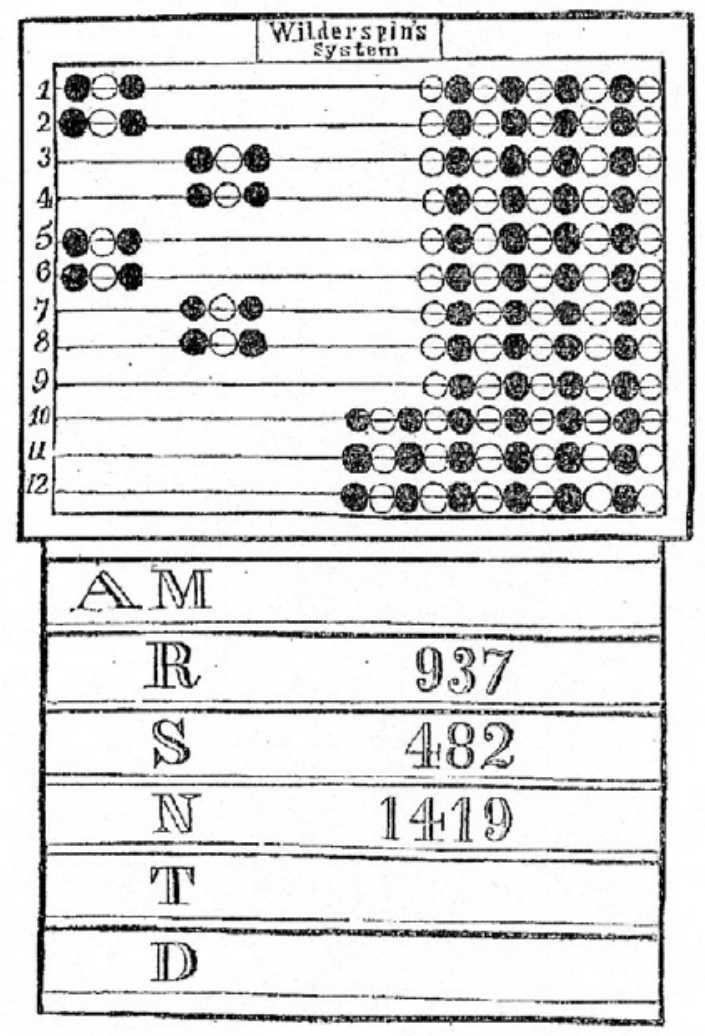

(b)

Figura 6. Tableros de bolas: Aritmeticón (a) y tablero contador de Wilderspin (b). ${ }^{33}$

Las propuestas de Vallejo y Montesino para el uso de los tableros contadores fueron la referencia sobre estos aparatos en España y, como tal, son citados por diversos autores.

\section{¿Ábacos o tableros contadores?}

Los aparatos como los de las figuras 4 (a) y 5 (a) reciben diferentes nombres tanto en las obras de referencia como en los catálogos de material

\footnotetext{
${ }^{32}$ Montesino, «Métodos especiales de enseñanza», 125.

${ }^{33}$ Wilderspin, The infant system, 225 y 228.
} 
escolar. En este trabajo los vamos a denominar ábacos o tableros contadores, según el uso que se haga de ellos, pues encontrar un aparato como los de las figuras 4 (a) y 5 (a) no es en absoluto suficiente para conocer cómo se enseña la aritmética en ese aula; se puede usar de dos formas muy distintas que diferenciaremos citándolos como ábaco o como tablero contador.

La diferencia fundamental en que en un ábaco el valor de cada bola depende de la posición que ocupa, del alambre en que se encuentra: el de las unidades, el de las decenas, el de las centenas... Es un material de enseñanza de la numeración posicional.

En los tableros contadores de enteros todas las bolas tienen el mismo valor; la unidad; no es un material posicional. Cuando se representa, por ejemplo, 35 en un aparato de esta índole, se utilizan efectivamente 35 bolas: tres alambres de diez bolas y cinco bolas más. Este tipo de uso ayuda a los niños a comprender el significado de ese número: son tres grupos de diez (decenas) y cinco unidades más.

En un ábaco, el número 35 se representa con cinco bolas en el alambre de las unidades y tres en el de las decenas. Proporciona también una buena representación del número, aunque no estén materialmente las 35 bolas. Este ha sido el uso del ábaco a lo largo de la historia y el que facilita la realización de las operaciones aritméticas.

A partir de la tercera década del siglo XIX, los aparatos que se utilizaron en las escuelas de párvulos y primarias eran tableros contadores, y ese fue su uso generalizado a lo largo del siglo (al menos). Sin embargo, se encuentran alusiones a su posible uso como ábaco. Montesino, en los artículos que escribió en $1843,{ }^{34}$ comenta que algunos autores ven más conveniente su uso como ábaco (lo describe pero no le da nombre), aunque él está en desacuerdo, pues opina que es mejor que cada decena se represente, efectivamente, por diez bolas.

Mariano Carderera, en su Diccionario de educación y métodos de enseñanza, dedica una voz al Ábaco. ${ }^{35}$ Describe el aparato, los dos tipos de uso del mismo con ejercicios para la escuela, señalando la mayor dificul-

\footnotetext{
${ }^{34}$ Montesino, «Métodos especiales», 125.

${ }^{35}$ Mariano Carderera, Diccionario de educación y métodos de enseñanza (Madrid: Imprenta de R. Campuzano, 1858, 2. ${ }^{\mathrm{a}}$ ed.), t. I, 1-8.
} 
tad cuando las bolas tienen un valor posicional, pero lo llama indistintamente ábaco y tablero contador.

\section{LOS ÁBACOS EN LOS CATÁLOGOS DE MATERIAL ESCOLAR}

\section{Modelos de aparatos}

En los catálogos consultados aparecen distintos modelos de ábacos o tableros contadores. A veces las diferencias son de diseño, pero otras influyen en la utilización de los mismos.

Hemos diferenciado varios tipos de estos aparatos, que vamos a describir y a identificar con una etiqueta.

\section{Tablero contador de enteros [E]}

Está formado por varias filas de diez bolas; generalmente son diez filas y, por tanto, tiene cien bolas; pero hay modelos con menos filas. Salvo ornamentación y dimensiones, responden a los tableros contadores de Vallejo y Montesino (figura 4 a y figura 5 a).

En la figura 7 hay uno del catálogo de 1881 de la casa Bastinos, y otro de 1935 de la casa Dalmau Carles Pla. Algunos llevan una pizarra tras la que pueden ocultarse las bolas que no se utilizan.

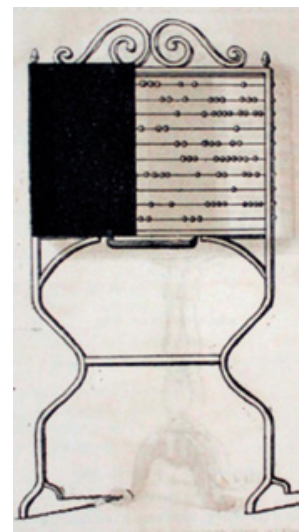

(a)

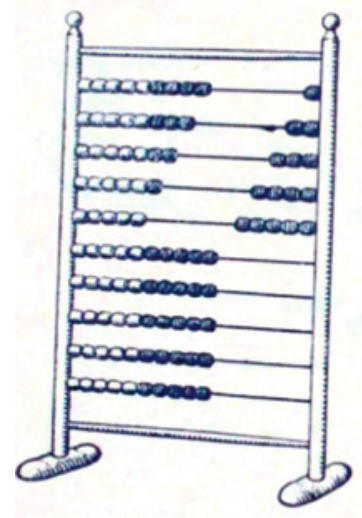

(b)

Figura 7. Tableros contadores de enteros: (a) de la casa Bastinos (1881), s.p. y (b) de la casa Dalmau Carles Pla (1935), 64. 
Otro modelo de este tipo es el plumier tablero contador del catálogo de 1935 de la casa Dalmau Carles Pla (figura 8). También es de 100 bolas.

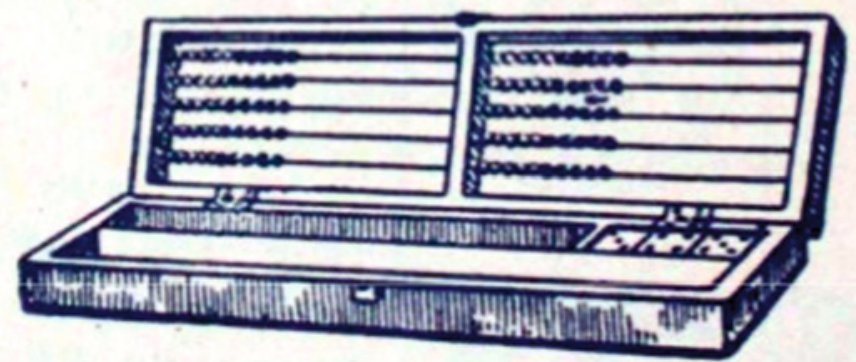

Figura 8. Plumier tablero contador de Dalmau Carles Pla (1935), 64.

Solo la casa Koehler-Volckmar ofrece un aparato "con 30 bolas en tres varillas para presentar todas las combinaciones de los números de 1 á 10, igualmente todos los ejercicios de 1 á 20 , respectivamente de 1 á 30 . De fácil manejo». ${ }^{36}$ Por tanto, se usa como tablero contador. No hay imágenes de este aparato.

La misma casa ofrece aparatos de lectura, y algunos modelos incluyen filas de bolas (figura 9). En el catálogo de 1928 lo describe así: «Gerting. Nuevo aparato de lectura. Con tabla de lectura, tablero contador de 20 bolas y caja para las letras». ${ }^{37}$

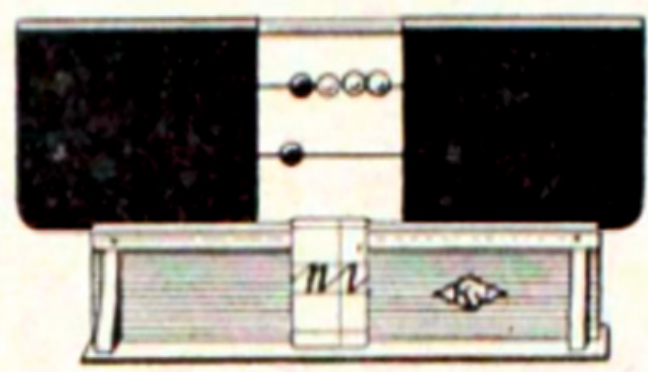

67030, pág. 25

Figura 9: Aparato de lectura con tablero contador. Catálogo de Koehler Volckmar (1928), 26.

\footnotetext{
${ }^{36}$ Volckmar, Catálogo, 43. También aparece con la misma descripción en la segunda edición del catálogo, no así en la de 1928.

${ }^{37}$ En los dos catálogos anteriores no hay ilustración.
} 


\section{Tablero contador de quebrados [Q]}

Los tableros contadores de quebrados siguen el modelo del de Vallejo (figura 4 (b)). En la segunda edición del catálogo de la casa Koehler se describe así: «Aparato para el estudio de números fraccionarios. De una forma parecida a la del aparato ruso, tiene este aparato 55 cilindros, siendo el tamaño de uno igual a 2, 3, 4, 5, 6, 7, 8. 9, 10 para demostrar de manera intuitiva el entero, la mitad de éste, y su tercera, cuarta, quinta, sexta, séptima, octava, novena y décima parte» ${ }^{38}$ (figura 10).

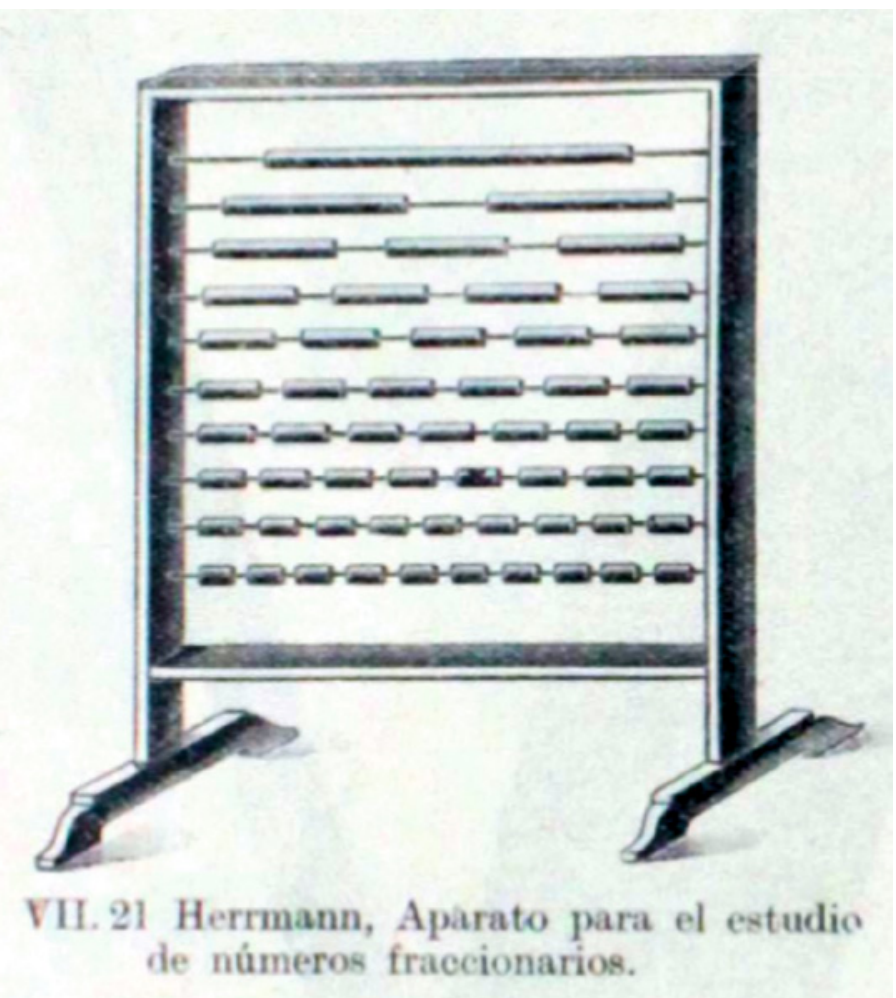

Figura 10: Aparato para el estudio de números fraccionarios. Catálogo Koehler (s.f,), 70.

El aparato de Vallejo tenía doce filas: el primer cilindro medía un pie, y cada uno de los doce del último alambre medía una pulgada (=1/12 pies).

\footnotetext{
${ }^{38}$ Koehler, Catálogo, 71.
} 
Tablero doble de enteros y de quebrados [D]

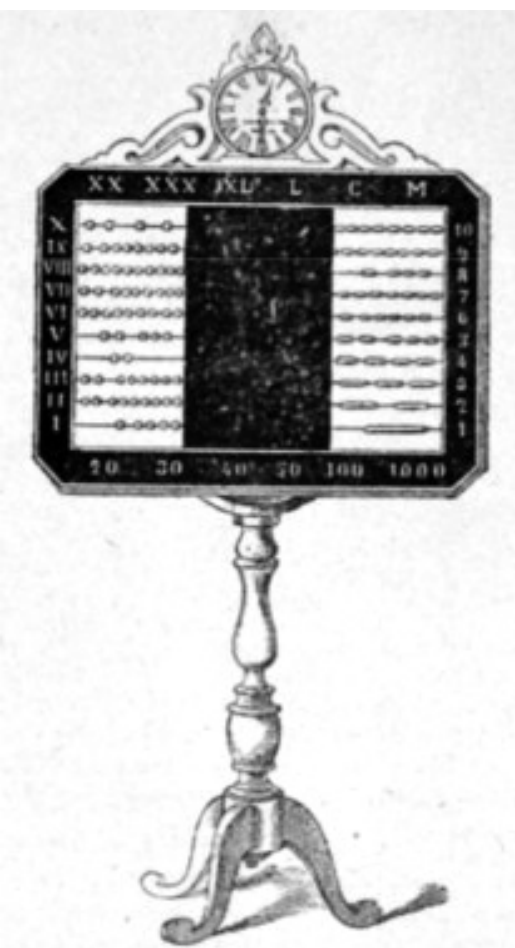

Figura 11. Tablero contador para enteros y quebrados. Catálogos casa Bastinos (1897), 135, (1905), 41.

Otro modelo incorporaba el tablero de enteros y el de quebrados en un mismo mueble. Este modelo lo proporcionaba la casa Bastinos. En la figura 11 se reproduce el que figuraba en sus catálogos de 1897 y 1905. Tras el panel de pizarra pueden ocultarse las bolas del tablero de enteros o cilindros del de quebrados. La ilustración es aproximada pues el cilindro unidad no equivale a los dos de la segunda fila ni a los tres de la tercera, etc.

Tablero de enteros con una fila adicional de cilindros para los quebrados [EQ]

Otra forma de integrar los tableros de enteros y quebrados es el modelo que presenta la casa Perelló y Vergés en su catálogo de 1915: a las diez 
filas del tablero de enteros se le añade otra con cilindros para representar las fracciones (figura 12).

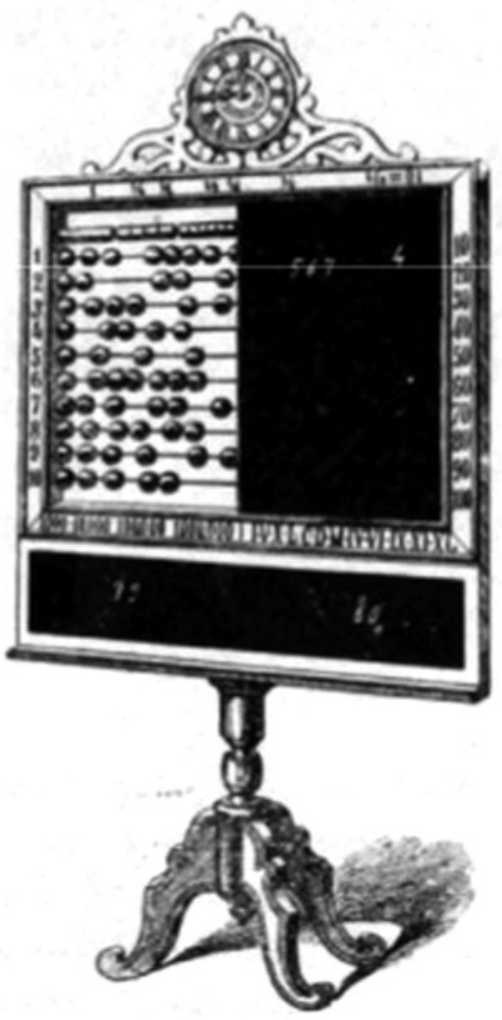

Figura 12. Tablero contador para enteros y quebrados. Catálogo casa Perelló y Vergés (1915), 37.

El catálogo solo dice que es un «tablero contador, para enteros y quebrados», ${ }^{39}$ pero no describe la fila correspondiente a los quebrados ni da indicaciones sobre su uso.

Tablero de enteros con cuadrados reversibles [C]

La casa Koehler Volckmar, en sus tres catálogos, presenta un «Fritsche. Nuevo aparato mecánico para el estudio de Aritmética, con cuerpos de cálculo movibles de dos colores y una tabla de cubierta» (figura 13).

\footnotetext{
${ }^{39}$ Perelló y Vergés, Catálogo, 37.
} 
«Los cuerpos numéricos, de construcción particular pero sencilla, no son bolas perforadas como las usuales, o cilindros, etc., sino placas cuadradas de dos colores que se pueden hacer girar». ${ }^{40}$

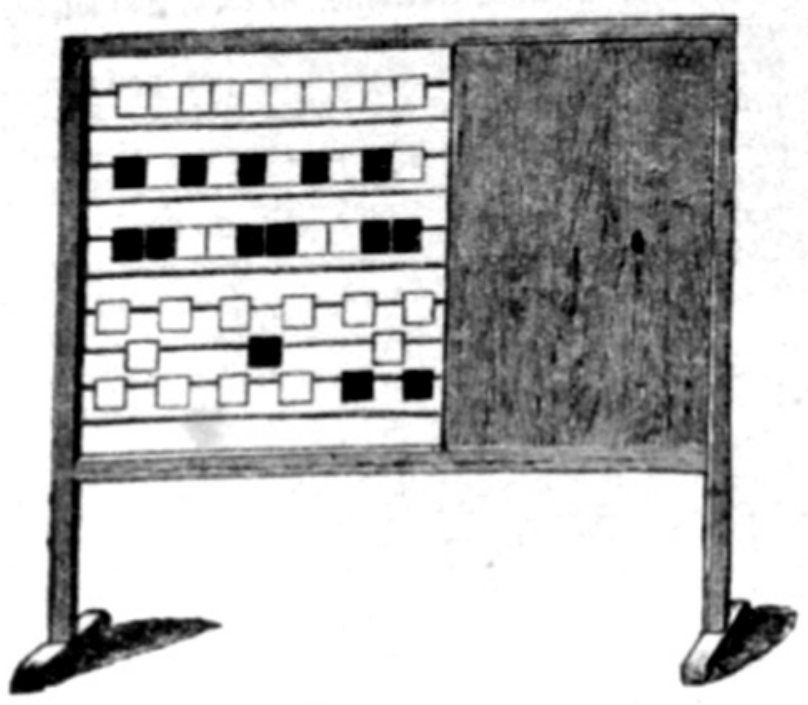

VII. 11 Fritsche, Nuevo aparato mecánico para cel estudio de Aritmética.

Figura 13. Fritsche. Nuevo aparato mecánico para el estudio de Aritmética. Volckmar (1910), 47.

La reversibilidad de las placas cuadradas permite visualizar las distintas descomposiciones de los números.

Tableros con las filas divididas en dos partes: $10+1$ o bien $10+n$ [G]

En algunos catálogos se ofrecen aparatos con los alambres divididos en dos zonas por una tablilla de madera.

${ }^{40}$ Volckmar, Catálogo, 43. 


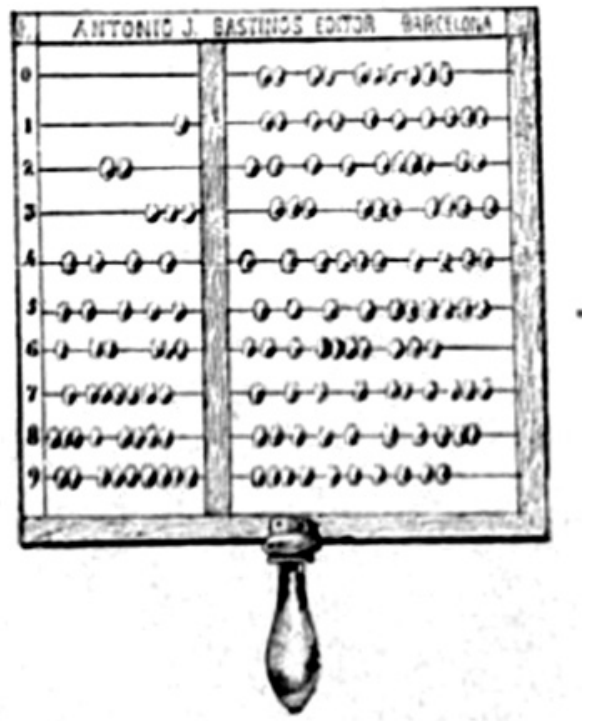

Figura 14: Tablero con las filas divididas, de la casa Bastinos (1897), 136

En unos casos, el efecto es el de agregar un aritmeticón (figura 6) a un tablero contador de enteros. El que presenta la casa Bastinos en su catálogo de 1897 puede verse en la figura 14. Lo denominan «Ábaco instructor ó tablero contador manual» y está dividido en dos casillas, «destinadas a las bolas que representan las decenas y las unidades, llevando en el marco la numeración». ${ }^{41} \mathrm{Al}$ hablar de bolas que representan las decenas y las unidades, parece sugerir un uso como ábaco, pero, en ese caso, aparecerían unidades de órdenes superiores, y no es así. En cualquier caso, no se describe el uso y éste no se deduce de la forma del aparato.

En el catálogo de Matías Real aparece un aparato con la misma descripción, pero sin ilustración.

En el catálogo de 1910 de la casa Volckmar y en el de Koehler (s.f.), aparece un aparato de bolas, de 10 alambres y 11 bolas por alambre, dividido cada uno de ellos en dos partes, con 10 y una bola (figura 15). Está descrito como «con 110 bolas en diez varillas con columnas de unidades

\footnotetext{
${ }^{41}$ Bastinos, Catálogo, 1897, 136.
} 
y decenas» ${ }^{42}$ pero sobre la parte de las filas de diez bolas pone «decenas». También aquí es dudoso su uso como ábaco pues no se citan unidades de mayor orden que las decenas y no está descrita la utilización.

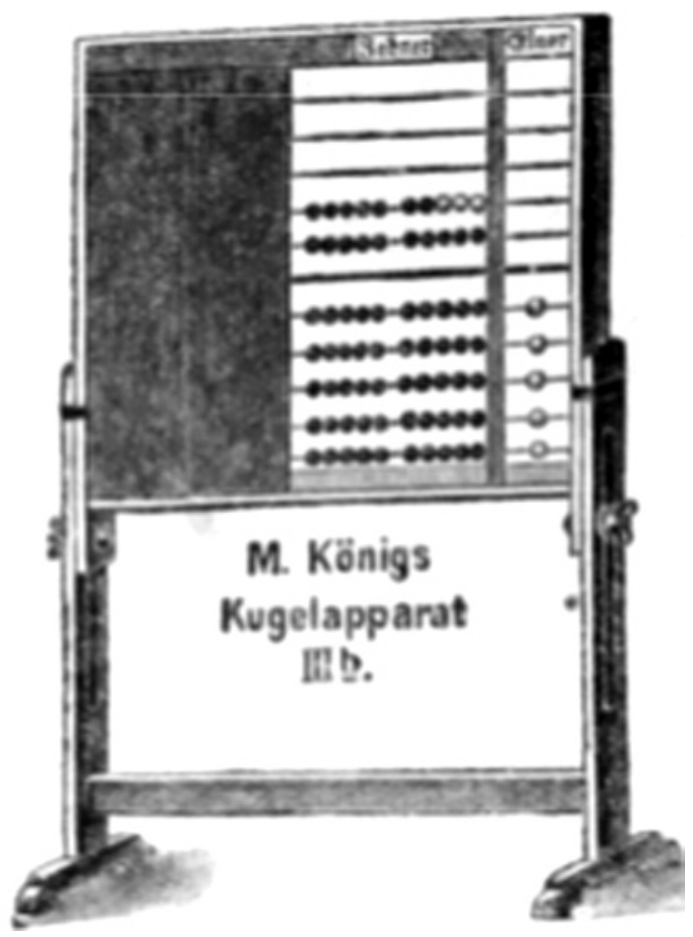

Figura 15: Tablero con las filas divididas. Volckmar (1910), 47 y Koehler (s.f.), 72.

Este aparato no aparece citado en el catálogo de 1928.

Tableros de 10 filas horizontales y 11 verticales [FC]

En el catálogo de Bazar Ibérico de 1914 y en el de Dalmau Carles Pla de 1935 aparece referenciado un aparato de diez alambres horizontales y once verticales (figura 16).

${ }^{42}$ Koehler, Catálogo, 71. 


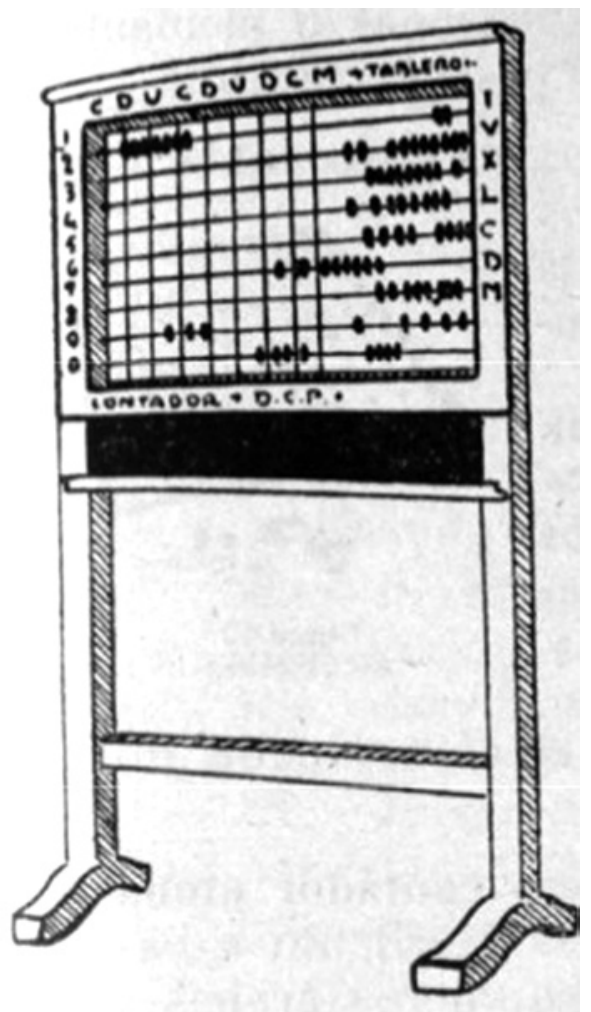

Figura 16: Tablero de diez filas y once columnas. Catálogo Dalmau Carles Pla (1935), 65.

En el catálogo de Bazar Ibérico no hay ilustración y lo describe como «Tablero contador o Abaco entero-decimal, contiene diez varillas horizontales, con bolas pintadas a 2 colores, y 11 varillas verticales, representando la lectura de cantidades hasta la decena de millón». ${ }^{43}$

En el catálogo de 1935 de Dalmau Carles Pla está la ilustración que hemos reproducido y la descripción es la misma que en el catálogo de Bazar Ibérico. Hay algunas incongruencias entre la descripción y la ilustración; por ejemplo, en el listón superior aparecen unas letras: C D U C D U D C M. Las tres últimas deben significar décimas, centésimas y milésimas, lo que es acorde con la denominación «ábaco entero decimal»; las seis primeras deben significar centenas, decenas y unidades, y eso

\footnotetext{
${ }^{43}$ Bazar Ibérico, Catálogo, 56.
} 
supone que se pueden representar números hasta la centena de millar, no hasta la decena de millón, como se afirma.

No se describe la utilización del aparato y la representación de las cantidades en el mismo es confusa ¿qué cantidad está representada en el aparato de la figura? Hay que tener en cuenta que las bolas se mueven por los alambres horizontales y parece que la función de los verticales es separar los diferentes órdenes de unidades ¿Cómo se representaría el número 999999 en este aparato?

\section{Tablero contador de Solana [S]}

En el catálogo de Antonio Pérez de 1911 (no en el de 1930) y en el de El Magisterio Español (s.f.) se cita un "tablero contador de Solana», del que no se da ninguna descripción ni ilustración. Tampoco hemos encontrado referencias al mismo en obras de Ezequiel Solana sobre la iniciación aritmética. ¿Tenía unas características específicas este tipo de aparato? o ¿se trata de una denominación propuesta por motivos comerciales, asociando a un tablero contador el prestigio de Ezequiel Solana?

\section{Referencia de los aparatos en los catálogos}

Los catálogos reflejan los objetos que ofrecen de diferentes formas; vamos a diferenciar dos:

- [B] Breve referencia al aparato: dan el nombre o una sucinta descripción de su apariencia; a veces señalan el campo numérico en el que se puede usar (enteros, fracciones, decimales). Se supone conocida su utilización e, incluso, la apariencia del objeto.

- [I] La presentación del aparato se acompaña con una imagen del objeto.

En ningún caso se ha encontrado descrito el uso de estos aparatos.

En un catálogo pueden aparecer diferentes modelos de un mismo tipo de aparato. A veces la diferencia está en las dimensiones; otras veces es distinto el diseño. 
Con las claves que se han definido, se ha elaborado un cuadro de recapitulación sobre estos aparatos en los catálogos (figura 17). En cada tipo de aparato se indica cómo se da la referencia al mismo y el número de aparatos de ese tipo que se citan.

Otro aspecto considerado es [N], el número de aparatos que aparecen en cada catálogo.

También se ha agregado una columna con el número de páginas de cada catálogo consultado.

\begin{tabular}{|c|c|c|c|c|c|c|c|c|c|c|}
\hline Catálogo & & & & & & & & & & $\mathbf{P g}$ \\
\hline & $\mathbf{N}$ & $\mathbf{E}$ & $\mathbf{Q}$ & D & EQ & $\mathbf{C}$ & G & FC & $\mathbf{S}$ & \\
\hline Bastinos, 1881 & 3 & $\mathrm{I}(2)$ & & I & & & & & & 150 \\
\hline Bastinos, 1897 & 5 & $\mathrm{I}(3)$ & & $\mathrm{I}$ & & & I & & & 220 \\
\hline Bastinos, 1905 & 4 & B I & & B I & & & & & & 78 \\
\hline Bazar Ibérico, 1914 & 9 & $\mathrm{~B}(6)$ & & $?$ & & & $?$ & B & & 462 \\
\hline Cultura, 1925 & 4 & $\mathrm{~B}(3)$ & $\mathrm{B}$ & & & & & & & 84 \\
\hline Cultura, 1927 & 2 & B I & & & & & & & & 38 \\
\hline Cultura, 1932 & 2 & $\mathrm{~B}$ & $\mathrm{~B}$ & & & & & & & 67 \\
\hline Cultura, 1934 & 2 & $\mathrm{~B}$ & $\mathrm{~B}$ & & & & & & & 241 \\
\hline Dalmau Carles, Pla, 1935 & 6 & $\mathrm{I}(4)$ & & ? & & & & I & & 255 \\
\hline Espasa Calpe, 1934 & 3 & $\mathrm{~N}(3)$ & & & & & & & & 231 \\
\hline Hernando, 1892 & 2 & $\mathrm{~B}$ & $\mathrm{~B}$ & & & & & & & 209 \\
\hline Hernando, 1894 & 0 & & & & & & & & & 168 \\
\hline Hernando, 1933 & 2 & $\mathrm{~B}$ & $\mathrm{~B}$ & & & & & & & 111 \\
\hline Koehler, sf & 18 & $\mathrm{I}(2) \mathrm{B}(10)$ & B I & & & B I & B I & & & 457 \\
\hline Koehler Vockmar, 1928 & 6 & I B(3) & & & & $\mathrm{B}(2)$ & & & & 306 \\
\hline Magisterio Español, sf & 1 & & & & & & & & B & 94 \\
\hline Perelló y Vergés, 1915 & 4 & $\mathrm{I}(1) \mathrm{B}(2)$ & & & $\mathrm{I}$ & & & & & 258 \\
\hline Antonio Pérez, 1911 & 4 & B I & I & & & & & & B & 176 \\
\hline Antonio Pérez, 1930 & 2 & $\mathrm{I}$ & $\mathrm{I}$ & & & & & & & 242 \\
\hline Matias Real, 1907 & 6 & $\mathrm{~B}(2)$ & B & & $\mathrm{B}(2)$ & & B & & & 129 \\
\hline Fernando Santarem, sf & 1 & B & & & & & & & & 85 \\
\hline Volckmar, 1910 & 10 & I B(5) & $\mathrm{B}$ & & & $\mathrm{I}$ & B I & & & 529 \\
\hline Totales & 97 & 59 & 11 & 6 & 3 & 6 & 7 & 2 & 2 & \\
\hline
\end{tabular}

Figura 17. Ábacos-tableros contadores en los catálogos de material escolar. 
El número de aparatos que aparecen en los catálogos consultados es de 97 y la cantidad por catálogo varía entre 0 y 18. El catálogo de Hernando de 1897 lo hemos incluido porque sus características son similares al resto de los catálogos y, sin embargo, no incluye aparatos de bolas, siendo este el único en el que ello sucede. Los catálogos que incluyen más aparatos son las dos primeras ediciones de las casas asociadas Koehler y Volckmar y el de Bazar Ibérico. En los tres casos se trata de catálogos que incluyen mucho material de importación: los dos primeros los edita una casa alemana, y el tercero era del representante de la casa American Seating Company Nueva York-Boston-Filadelfia.

Se puede decir que, en esta época, en los catálogos que incluyen material escolar para matemáticas, aparece algún tablero contador.

Las dos terceras partes de los aparatos corresponden a los clásicos tableros contadores de enteros, y más del $80 \%$ responden a los modelos de aparatos de Vallejo, de enteros y quebrados (figura 4); el resto son variantes sobre dichos modelos.

Hay algunos aparatos que, con la información que ofrece el catálogo, no es segura su adscripción; los hemos señalado con el signo ? en el cuadro de la figura 17. Son tres casos:

- «Tablero contador o Abaco torneado, contiene diez varillas con bolas o cilindros, pizarra corredera». ${ }^{44}$ Se ha considerado un aparato doble [D], con bolas en los diez alambres y un lado y cilindros en los diez alambres del otro, de forma similar a la figura 11.

- «Tablero contador, manual, dividido en dos compartimentos para mejor simplificar la lectura de cantidades». ${ }^{45}$ No se sabe cómo son esos dos compartimentos. Se ha considerado del tipo [G]; podría ser como el de la figura 14 o el de la figura 15.

- «Tablero contador global D.C.P. Para ejercicios de cálculo a base de enteros, quebrados, números árabes y romanos, indicaciones horarias y grados cegesimales». ${ }^{46}$ Con esa descripción es difícil saber cómo es el aparato; se ha situado como tablero doble [D], pero podría considerarse en otros apartados.

\footnotetext{
${ }^{44}$ Bazar Ibérico, Catálogo, 56.

45 Bazar Ibérico, Catálogo, 56.

${ }^{46}$ Dalmau Carles, Pla, Catálogo, 66.
} 
No hay ningún caso en el que se describa el uso de estos aparatos, aunque algunos catálogos sí lo hacen con otros de los materiales que ofrecen. Parece que se considera que estos aparatos son conocidos, no son novedosos y se saben usar, y que, por tanto, basta nombrarlos y, en todo caso, dar una somera descripción de los mismos, incidiendo en muchas ocasiones en el diseño. En el 80\% de los casos (que responden a los bastidores de Vallejo) es suficiente, pues hay obras en las que se describe su uso; pero eso no ocurre con el $20 \%$ restante y resulta difícil interpretar lo que se oferta.

Además, en algunos tableros hay informaciones cuya utilización no se sabe cuál puede ser. Por ejemplo, en el marco de los tableros contadores de los catálogos de Bastinos hay números romanos y arábigos: del 1 al 10 y las decenas, de 20 a 100 (figura 12) ¿por qué esos y en ese lugar? ¿nos indican algo sobre el uso que se les daba a estos aparatos? Y en el aparato de tipo [FC] de la casa Dalmau Carles Pla (figura 16), ¿qué función tienen las cifras del 1 al 9 y el 0, situadas a un lado del aparato? ¿y los símbolos de los números romanos, situados en el otro lado?

Otro aspecto a considerar es la denominación de los aparatos. Lo más habitual es llamarlos «tablero contador», añadiendo «de enteros» o «de quebrados», según el caso. Pero hay variantes, y son especialmente significativas las evoluciones de la denominación dentro de una misma casa comercial.

En el catálogo de 1881 de la casa Bastinos, el tablero contador de enteros dice que es "para enteros y decimales", mientras que el doble (como el de la figura 11) dice que es "para enteros y decimales», lo que es erróneo. En sucesivas ediciones, los catálogos de esa casa lo denominan de la forma habitual: «tablero contador de enteros» $\mathrm{y}$ «tablero contador de enteros y quebrados», respectivamente.

La casa Bastinos solo llama «Abaco instructor o tablero contador manual» al de tipo [G] (figura 14), al igual que la casa Matías Real, que lo copia.

Otras casas en las que la denominación varía en el tiempo son las alemanas Koehler y Volckmar. En el primer catálogo en castellano, de 1910, llaman ábacos a estos tres aparatos: ábaco ruso (al de enteros), ábacos de quebrados y ábaco nuevo de Fritsche, al de tipo [C]. La denominación de 
ábaco para ese tipo de aparatos no era habitual en España. En la segunda edición las descripciones son similares, pero se suprime la denominación de ábaco y se le llama, por ejemplo, «aparatos para la enseñanza de la aritmética rusos», y, en un caso, agrega «tableros de contador». En la edición de 1928 hay menos oferta de este tipo, pero los denomina «Tablero de contador, marca $\mathrm{K}-\mathrm{V}$ », en el caso de los de enteros, $\mathrm{y}$ «Fritsche. Nuevo aparato mecánico para el estudio de la aritmética» (sin descripción ni ilustración) en el aparato de tipo [C].

También utiliza la denominación ábaco la casa Bazar Ibérico (representante en España de una casa estadounidense), pero no se advierte el criterio usado para dar dicha denominación. De los nueve aparatos que presenta, cuatro los denomina «tablero contador» y cinco «tablero contador o ábaco»: a tres de los aparatos que son claramente tableros contadores de enteros les añade el calificativo de ábaco (no a los otros tres), mientras que hay uno, de tipo [G], que sugiere el uso de decenas y unidades, que solo se le denomina "tablero contador».

En cuanto a los aparatos del tipo [FC], que son en los que más claramente se sugiere su uso como ábaco, la casa Bazar Ibérico los denomina «Tablero contador o ábaco entero-decimal», mientras que para la casa Dalmau Carles Pla es un tablero contador.

\section{COMPARACIÓN DE LAS PROPUESTAS DE LOS CATÁLOGOS}

El estudio de los catálogos de material escolar requiere comparar las ofertas que realizan, tanto considerando los de una misma casa comercial como contrastando la oferta de las distintas casas. Para ello, se puede considerar el número de aparatos de cada tipo que ofertan, la denominación de los mismos, así como las descripciones e ilustraciones que se proporcionan.

Los catálogos son un escaparate de las intenciones de la casa comercial que los edita y reflejan los cambios en política comercial, cambios ligados, en ocasiones, a variaciones en la titularidad de la empresa, bien por herencia (librería Antonio Pérez), por separación de los socios (Bastinos 1881 y 1897) o por la llegada de otros nuevos (Cultura, entre 1925 y 1927). Hemos constatado que estas variaciones provocan, a veces, un nuevo impulso; otras, una reducción de las expectativas (Bastinos, 1905). 
Hay que valorar la existencia o no de ese impulso y uno de los índices es el tamaño de los catálogos (que hemos recogido en la tabla de la figura 17), que hay que aplicar críticamente pues, en ocasiones, lo que refleja es un cambio en el tipo de productos que ofertan.

\section{Evolución de los aparatos en los catálogos de una casa comercial}

En el conjunto de catálogos que estamos utilizando, hay cinco casas comerciales de las que se dispone de más de un catálogo: Antonio Pérez (2 catálogos), Bastinos (3), Cultura (4), Hernando (3) y Koehler-Volckmar (3); en ellos se puede valorar la estabilidad y el cambio en la oferta.

Veamos las cinco series de que disponemos.

\section{Antonio Pérez}

Hay 19 años de diferencia entre ambos catálogos. El catálogo de 1911 tiene 176 páginas, 66 de ellas dedicadas a material escolar; y el de 1930, 242 páginas, 121 de material escolar. Este último está más cuidado, con mejor encuadernación e índices. El aumento de páginas se debe a la parte de material escolar en la que ha mejorado algunas secciones, en particular la de mobiliario escolar, que pasa de una a seis páginas.

Hay mucho en común entre ambos catálogos, tanto en los objetos ofertados como en las imágenes; por ejemplo, el encerado que ofertan con una imagen en la que figura una operación de multiplicar (páginas 37 y 17 respectivamente).

En el de 1911 se ofertaban cuatro aparatos y en el de 1930 dos, pues han desaparecido el "contador Solana» y un "tablero contador de enteros con pie torneado» que costaba más del doble que los otros. 


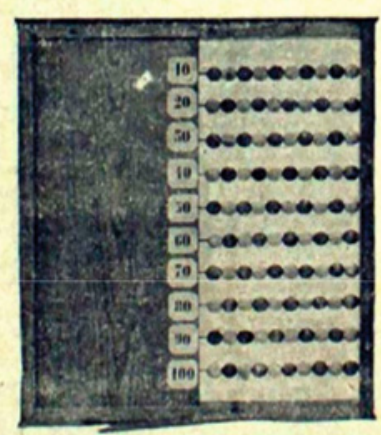

Contador enteroes.

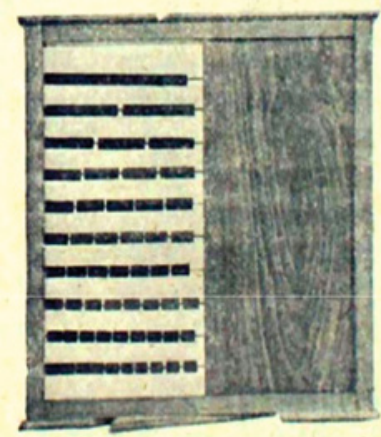

Contador quebrados.
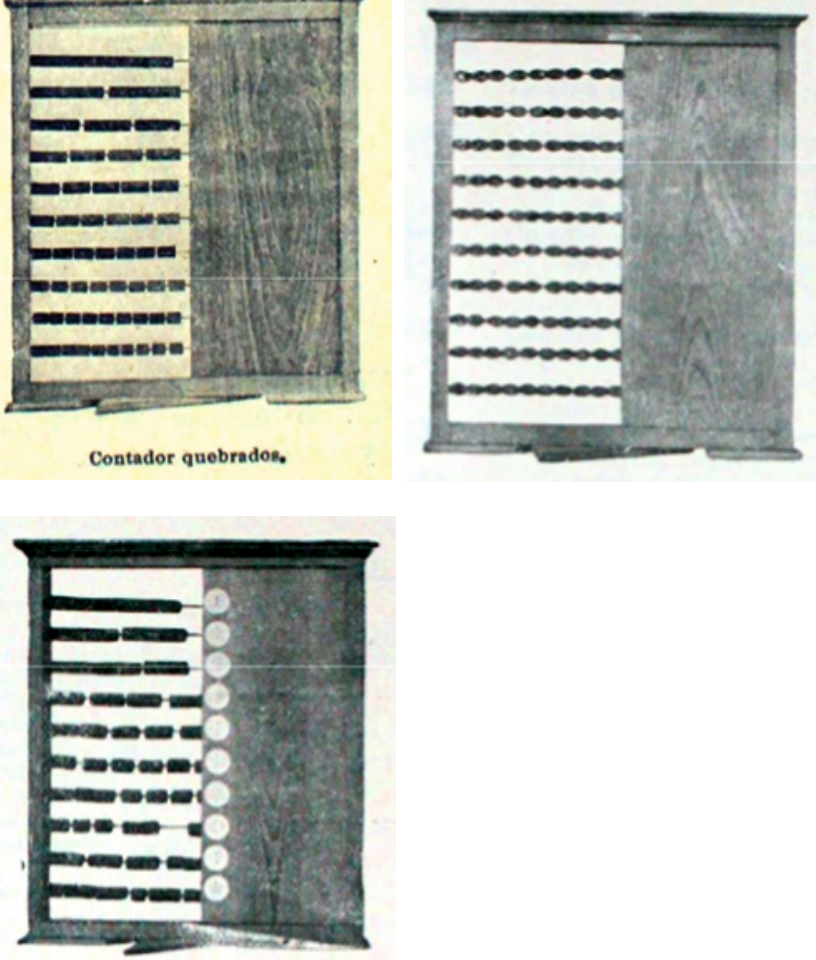

Figura 18. Tableros contadores de la casa Antonio Pérez: (a) del catálogo de 1911, 33 y (b) del catálogo de 1930, 15.

Las ilustraciones son muy similares, aunque en 1911 en cada fila del tablero de enteros apareciera escrita la decena $(10,20, \ldots 100)$; en el tablero de quebrados es en el de 1930 en el que se han colocado los números del 1 al 10 para indicar en cuántas partes se ha dividido el cilindro unidad.

\section{Bastinos}

Los catálogos son de 1881, 1897 y 1905. Salvo uno de 1905, todos los aparatos ofertados van acompañados de ilustración, lo que facilita su comparación. El catálogo de 1897 ofrece cinco aparatos, uno de los cuales (sistema prusiano, figura 19 (a)) tiene la misma ilustración que otro de 1881; el tablero doble ([D], figura 11) es igual a los de 1881 (con el añadido de un reloj) y 1905, y hay otro modelo de tablero de enteros 
que comparte con uno de 1905 (figura 19 (b)). Además, hay dos modelos que solo se presentan en 1887: un tablero de enteros y el tablero de tipo [G] (figura 14).

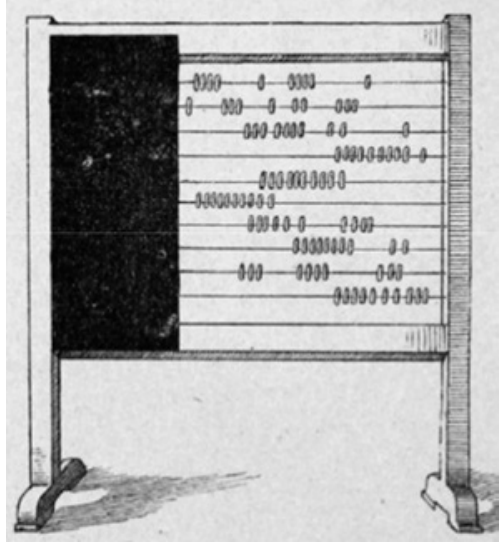

(a)

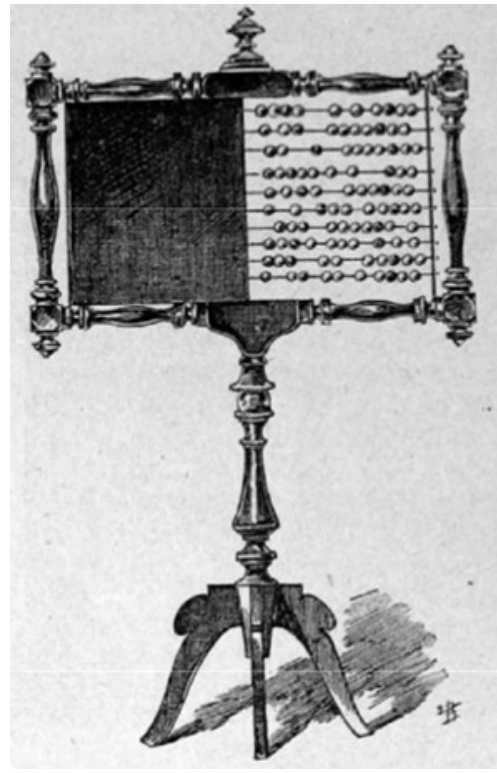

(b)

Figura 19. Tableros contadores de la casa Bastinos: (a) sistema prusiano (catálogos 1881, s.p. y 1897, 137) y (b) tablero de enteros torneado (catálogos de 1897, 137, y 1905, 40).

Ya hemos comentado las diferencias en la denominación entre el catálogo de 1881 y los otros dos.

El catálogo de 1905, de Sucesores de Julián Bastinos, tiene un número mucho menor de páginas (78, a comparar con las 150 y 220 de los anteriores) y no hace referencia a que se trate de material propio. Los catálogos de 1881 y 1897 destacan que solo recogen material propio de la casa.

\section{Cultura}

Los catálogos de la casa Cultura son de los años 1925, 1927, 1932 y 1934. Ofrecen pocos tableros contadores (10 en total, de tipo [E] y [Q]) y solo una ilustración. Esto contrasta con la abundancia de la oferta e ilustraciones de otros tipos de material, entre ellos, de matemáticas. 
En el catálogo de 1925 y en el de 1932, las dimensiones de uno de los aparatos [E] y del aparato [Q] son 57 x $51 \mathrm{~cm}$, que coinciden con las de los que oferta la casa Hernando; dadas las cantidades involucradas, sugieren la existencia de un proveedor común que proporcionaba aparatos, al menos, desde 1892. Las dimensiones de los que se ofertan en 1925 y en el resto de los catálogos de la casa son diferentes a estas y entre sí, lo que sugiere que no eran realizados por ellos y que recurrían a una variedad de fabricantes.

\section{Hernando}

Los catálogos de la casa Hernando son de 1892, 1894 y 1933; es decir, cubren un período de 41 años. Solo ofrecen dos tableros contadores los catálogos de los años 1892 y 1933 y ninguno en 1894. Son los típicos de enteros y quebrados y no hay ninguna ilustración. La descripción de la calidad del aparato y su finalidad es idéntica en 1892 y 1905; también lo es el tamaño de los mismos ( 57 x 51 centímetros). La ausencia de oferta en 1894 más parece una errata u olvido, pues no tiene sentido que no dispusieran de ellos.

\section{Koehler-Volckmar}

La casa Koehler-Volckmar es la que más aparatos oferta, sobre todo en el catálogo de 1910 (10 aparatos) y en la segunda edición (sin fecha) con 18 aparatos; en la edición de 1928 se ofertan 6, lo que la sitúa en el cuartil superior.

Son fabricantes de material escolar y los productos ofertados se mantienen a lo largo del tiempo, aunque varíe la denominación de los mismos, como ya hemos comentado. De algunos tipos son los únicos que ofertan, como el «Fritche» (figura 13) de elementos cuadrados de dos colores, que aparece en todos los catálogos, con ilustración en los dos primeros, o los de tablero partido, con 110 bolas (tipo [G], figura 15), que aparece, con ilustración, en los dos primeros catálogos. También ofertan en todos sus catálogos aparatos con dos o tres filas de diez bolas, tanto aislados como asociados a un aparato de lectura (figura 8). 


\section{Estabilidad y cambio en los catálogos}

En una primera apreciación, se advierte que los nuevos catálogos recogen en gran medida la oferta de los anteriores. Es lo esperado pues no es probable que las casas comerciales renovaran gran parte de su material.

Tanto las descripciones como las ilustraciones son las mismas o muy parecidas, con pequeños cambios. Los tableros contadores no se describen o se hace de forma muy somera, por lo que no queda claro el uso que sugieren para ellos. La propia denominación como tablero contador o como ábaco tampoco es significativa; esto es particularmente evidente en la variación de la denominación en los distintos catálogos de Koehler-Volckmar, que hemos comentado, para adaptarse a denominaciones corrientes en España, y en la falta de coherencia de las denominaciones en el catálogo de Bazar Ibérico que presenta, sobre todo, material de importación y cuyas denominaciones debe traducir y adaptar.

Con ese tipo de descripción hay dificultades para saber si los aparatos que se ofertan en distintos catálogos son los mismos. Lo facilita si la propuesta está acompañada de una ilustración, como ocurre con los de la casa Bastinos o la casa Koehler-Volckmar, lo que nos ha permitido confirmar su estabilidad. De los 97 aparatos censados, 27 van acompañados de ilustración (el 28.4\%). En los catálogos de las casas Espasa-Calpe, Fernando Santarén, Hernando y Matías Real no hay ninguna imagen y entre los cuatro catálogos de la casa Cultura solo una.

Otro índice que ha permitido comparar aparatos es la dimensión de los mismos, aunque este dato no aparece en muchos catálogos. De esta forma se ha podido establecer el origen común de aparatos de las casas Hernando y Cultura, así como la variación de proveedores para esta última casa en el caso de los tableros contadores.

La descripción del aparato tipo [G] del catálogo de 1897 de Bastinos (figura 14) es idéntica a la de Matías Real (1907), lo que permite afirmar que son el mismo aparato. En la figura aparece como autora la casa Bastinos, sin embargo, ese aparato no se oferta en el catálogo de Bastinos de 1905 y sí dos años después por Matías Real. Se plantea así la cuestión de la autoría de los materiales escolares, tanto de la idea como de su realización. Los catálogos de material escolar son una fuente importante para dar respuesta a esta cuestión, teniendo en cuenta que la informa- 
ción que proporcionan viene mediatizada por su objetivo comercial y debe ser contrastada con otras fuentes. El que este aparato solo aparezca en el catálogo de 1897 y no en 1907 parece indicar que proviene de otro artesano aunque, debido al prestigio de la casa Bastinos, que publicitaba objetos "fabricados bajo nuestra dirección», ${ }^{47}$ grabara el nombre de la casa comercial en el aparato. No podemos saber si el nombre de Bastinos figuraba en el que ofertaba Matías Real. Pero también hay que tener en cuenta que en 1905 el catálogo de Bastinos se redujo considerablemente, y se pudo decidir no colocar un aparato en el cual una de las dos partes de las que constaba no tenía una función especial.

Una cuestión similar se plantea con el aparato de tipo [FC] que ofertan Bazar Ibérico y Dalmau Carles, Pla y cuya descripción es la misma. En el catálogo de Dalmau Carles Pla, se reivindica la autoría: lo denomina «Tablero contador DCP» [Dalmau Carles Pla], y así está grabado en la imagen que acompaña (figura 16). Sin embargo, ya lo ofertaba una casa dedicada fundamentalmente a la importación, Bazar Ibérico, 21 años antes.

Se constata así que los modelos se copian, no solo la idea sino muchas características de su realización. Por ejemplo, la ilustración del aparato de tipo [EQ] de la casa Perelló y Vergés es muy similar a los aparatos que oferta la casa Bastinos, la cual no ofrece aparatos de tipo [EQ] (ver figura 2).

${ }^{47}$ Bastinos, Catálogo, 1881, s.p. 


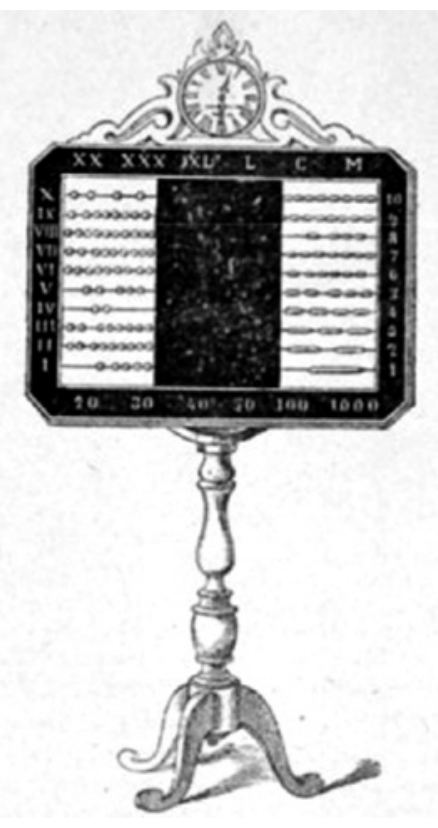

(a)

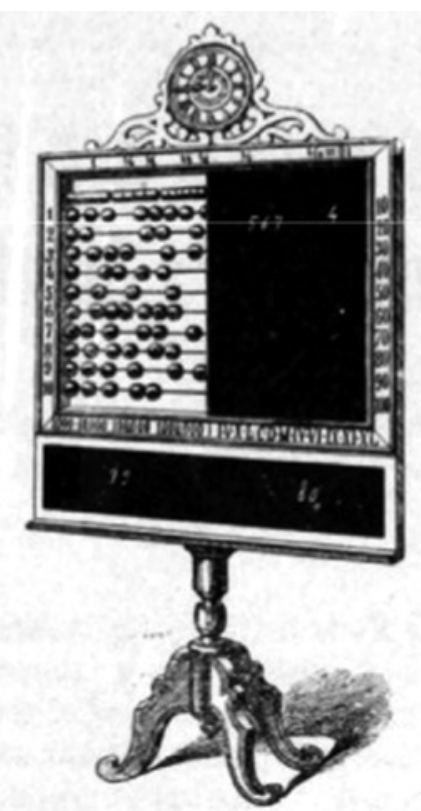

(b)

Figura 20. (a) Tablero contador doble de enteros y quebrados de la casa Bastinos (1897), 135, y (b) tablero contador para enteros y quebrados de Perelló y Vergés (1915), 37.

Aunque hay datos que indican que en España se conocía la diferencia de uso como tablero contador y como ábaco ${ }^{48}$ el uso que se propone desde los catálogos es fundamentalmente como tablero contador. En los aparatos que sugieren un cierto valor posicional de las bolas (tipo [G] y [FC]) no se describe bien su uso y éste no se deduce claramente del diseño del aparato.

Hay aparatos que aparecen en un catálogo y desaparecen en los siguientes, como es el caso del tipo [G] de la casa Bastinos. Suelen ser los más sofisticados. En los aparatos estudiados, al estar muy tipificados hay pocos ejemplos, pero podemos ver esta cuestión con los aparatos para la demostración del Teorema de Pitágoras. En los catálogos alemanes Koehler y Koehler- Volckmar se ofertan dos aparatos, uno para "demostrar» el teorema de Pitágoras en el caso, típico, de un triángulo de lados enteros de medida 3-4-5, con cuadrados cuadriculados, y otro que «demues-

\footnotetext{
${ }^{48}$ Montesino, «Métodos especiales de enseñanza», 125. Carderera, Diccionario de educación, 1-8.
} 
tra el teorema de Pitágoras para un triángulo cualquiera. El cuadrado de la hipotenusa puede descomponerse de modo que de sus partes se forman dos cuadrados iguales á los de los catetos». ${ }^{49}$ En la casa Cultura, el catálogo de 1925 oferta los dos aparatos con la misma descripción, en el segundo, que los catálogos alemanes; en los tres posteriores catálogos de la casa Cultura estudiados (1927, 1932 y 1934) solo se ofrece el del triángulo 3-4-5.

\section{CONCLUSIONES}

Los catálogos de material escolar son una fuente importante para el estudio de la HEM pues informan de los objetos que podían ser utilizados para la enseñanza de las matemáticas en un determinado momento. Pero hay que tener en cuenta los condicionantes de este tipo de objeto, el catálogo, marcado en muchas ocasiones por el carácter comercial de las casas que los editaban.

Para estudiar esas potencialidades y límites en el trabajo se utilizan unos aparatos, denominados ábacos o tableros contadores. Se trata de aparatos prototípicos de la enseñanza de la aritmética que aparecen en casi todos los catálogos de material escolar. Una característica de estos aparatos, que ha resultado útil en nuestro trabajo, es que se puede hacer uso de los mismos de dos maneras muy diferentes, que han sido caracterizadas y denominadas una, tablero contador, y otra, ábaco. Su utilización de una u otra forma se remonta al siglo XIX y se asocia a métodos de enseñanza de la aritmética intuitivos, los cuales tienen su origen en Pestalozzi.

En el trabajo se han identificado los modelos de estos aparatos que se ofrecen en los catálogos de material escolar y las indicaciones que se dan sobre su uso.

Hemos constatado en varias ocasiones que los editores de los catálogos parece que no conocen bien el uso y la utilidad de los materiales que ofertan:

- En las erróneas denominaciones que se dan a los aparatos en el catálogo de 1881 de Bastinos.

${ }^{49}$ Koehler, Catálogo, 77. 
- En el uso inconsistente de «ábaco» o «tablero contador» que hace Bazar Ibérico.

- En las descripciones incompletas de los mismos que dificultan su catalogación o la comprensión de su uso (como en los aparatos de tipo [FC]).

- En la falta de indicaciones sobre la composición y el uso de la barra de cilindros en los aparatos de tipo [EQ].

- En la utilización en los aparatos de elementos no directamente relacionados con su uso, como los números (árabes y romanos) que aparecen en el marco.

Los catálogos de material escolar son una fuente importante para estudiar el origen y la autoría de los objetos que se utilizan en las actividades de enseñanza. Para ello se requiere contar con colecciones de una y de varias casas comerciales y eso, ya se ha señalado, es difícil por ser considerados los catálogos, prácticamente, como un material fungible. Otra fuente de dificultad que hemos constatado es la prevalencia de la finalidad comercial de estas fuentes, que lleva a copiar aparatos y a atribuir la autoría a la propia casa comercial, así como a descripciones poco exactas, destacando los aspectos más comerciales, sean o no pertinentes en su uso. Es necesario, por tanto, contrastar los datos obtenidos de los catálogos con otras fuentes como libros de metodología didáctica o libros de texto. Este es un estudio que estamos realizando.

\section{Nota sobre la autora}

Dolores Carrillo Gallego es Licenciada en Ciencias Matemáticas por la Universidad de Zaragoza y Licenciada y Doctora en Pedagogía por la Universidad de Murcia. En la actualidad es profesora titular del Área de conocimiento "Didáctica de las Matemáticas», y su docencia ha estado dirigida a la formación del profesorado en ese ámbito. Sus líneas de investigación prioritarias son la Historia de la Educación Matemática y la Didáctica de las Matemáticas en la Educación Infantil. Ha sido subdirectora de la Escuela de Magisterio de la Universidad de Murcia y vicedecana de la Facultad de Educación. Es miembro del Centro de Estudios sobre la Memoria Educativa (CEME) de la Universidad de Murcia desde su fundación y forma parte del equipo que gestiona el funcionamiento del Museo 
Virtual de Historia de la Educación (MUVHE). Ha sido secretaria del CEME (2013-2017) y, en la actualidad, es directora del mismo.

\section{Referencias}

Bernal, José M., J.D. LóPez y P.L. Moreno. «Museos pedagógicos y enseñanza de las ciencias: de las láminas y colecciones a los recursos didácticos virtuales». In I Encontro Iberoamericano de Museos Pedagóxicos y museólogos de la educación, 413-426. Santiago de Compostela: Xunta de Galicia, 2008.

CARDERERA, Mariano. Diccionario de educación y métodos de enseñanza. Tomo I. Madrid: Imprenta de R. Campuzano, 1858.

Chavannes, Daniel A. Exposicion del método elemental de Henrique Pestalozzi. Madrid: Imprenta de Gomez Fuentenebro,1807.

ESTEBAN, León. (1997): «Los catálogos de librería y material de enseñanza como fuente iconográfica y literario escolar». Historia de la Educación 16 (1997): $17-46$.

IFRAH, Georges. Las cifras. Historia de una gran invención. Madrid: Alianza Editorial, 1987.

Juliá, Dominique. «La culture scolaire comme objet historique». In Colonial experience in Education. Historical Issues and Perspectives, Gent, Paedagogica Historica, Supplementary series I (1995): 353-382.

MARTínez RuIz-Funes, María J. «Los catálogos de material de enseñanza como fuente para el estudio de la cultura material: la recepción y difusión del Método Froebel en España». In Patrimonio y Etnografía en España y Portugal durante el siglo $X X$, edited by Pedro L. Moreno Martínez y Ana Sebastián Vicente, 265-277. Murcia: Sociedad Española para el Estudio del Patrimonio Histórico-Educativo (SEPHE) y Centro de Estudios sobre la Memoria Educativa (CEME) de la Universidad de Murcia, 2012.

Montesino, Pablo. «Métodos especiales de enseñanza. Enseñanza de la aritmética». Boletín Oficial de Instrucción Pública, V (1843): 77-84, 122-128, 178190.

- Manual para los maestros de las escuelas de párvulos. Madrid: Imprenta del colegio de sordo-mudos y ciegos, 1850.

Moreno, Pedro L. «History of School Besk Development in Terms of Hygiene and Pedagogy in Spain (1838-1936)». In Materialities of Schooling: Design - Tecnology - Objects - Routines, edited by M. Lawn y I. Grosvenor, 71-95. Oxford: Symposium books, 2005.

- «El mobiliario escolar en los catálogos de material de enseñanza: consideraciones metodológicas». In La infancia en la historia: espacios y representaciones, edited by P. Dávila, y L.M. Naya, 342-355. San Sebastián: Erein, 2005. 
Moreno, Pedro L. y Ana Sebastián. «Los catálogos de material de enseñanza y la cultura material de la escuela. La colección del Centro de Estudios sobre la memoria Educativa (CEME) de la Universidad de Murcia». In Patrimonio y Etnografía en España y Portugal durante el siglo XX, edited by Pedro L. Moreno Martínez y Ana Sebastián Vicente, 293-309. Murcia: Sociedad Española para el Estudio del Patrimonio Histórico-Educativo (SEPHE) y Centro de Estudios sobre la Memoria Educativa (CEME) de la Universidad de Murcia, 2012.

Pancorbo, Luis, M.V. Becerra, R. Martínez y R. Rodríguez. Matemáticas 1. Madrid: Mc Graw Hill, 1995.

Pestalozzi, Johan E. Cómo Gertrudis enseña a sus hijos. Cartas sobre la educación de los niños. Libros de educación elemental (prólogos). México: Porrúa, 1980.

VAllejo, José Mariano. Ideas primarias que deben darse a los niños en las escuelas acerca de los números al tiempo que se están ejercitando en la clave analítica de la lectura. Madrid: Imprenta de D. Miguel de Burgos, 1833.

VIÑAO, Antonio. Sistemas educativos, culturas escolares y reformas. Madrid: Morata, 2002.

WiLDERSPIN, Samuel. The infant system for Developing the Intellectual and Moral Powers of all Children, from One to Seven Years of Age. London: James S. Hodson, 1840. 